\title{
Ferritin and ferritin isoforms I: Structure-function relationships, synthesis, degradation and secretion
}

\author{
A. M. KOORTS \& M. VILJOEN \\ Department of Physiology, School of Medicine, University of Pretoria, Pretoria, South Africa
}

\begin{abstract}
Ferritin is the intracellular protein responsible for the sequestration, storage and release of iron. Ferritin can accumulate up to 4500 iron atoms as a ferrihydrite mineral in a protein shell and releases these iron atoms when there is an increase in the cell's need for bioavailable iron. The ferritin protein shell consists of 24 protein subunits of two types, the H-subunit and the L-subunit. These ferritin subunits perform different functions in the mineralization process of iron. The ferritin protein shell can exist as various combinations of these two subunit types, giving rise to heteropolymers or isoferritins. Isoferritins are functionally distinct and characteristic populations of isoferritins are found depending on the type of cell, the proliferation status of the cell and the presence of disease. The synthesis of ferritin is regulated both transcriptionally and translationally. Translation of ferritin subunit mRNA is increased or decreased, depending on the labile iron pool and is controlled by an ironresponsive element present in the 5'-untranslated region of the ferritin subunit mRNA. The transcription of the genes for the ferritin subunits is controlled by hormones and cytokines, which can result in a change in the pool of translatable mRNA. The levels of intracellular ferritin are determined by the balance between synthesis and degradation. Degradation of ferritin in the cytosol results in complete release of iron, while degradation in secondary lysosomes results in the formation of haemosiderin and protection against iron toxicity. The majority of ferritin is found in the cytosol. However, ferritin with slightly different properties can also be found in organelles such as nuclei and mitochondria. Most of the ferritin produced intracellularly is harnessed for the regulation of iron bioavailability; however, some of the ferritin is secreted and internalized by other cells. In addition to the regulation of iron bioavailability ferritin may contribute to the control of myelopoiesis and immunological responses.
\end{abstract}

\section{Introduction}

Ferritin is the major intracellular protein involved in the storage and release of intracellular iron and since iron is needed in various cellular functions it does not come as a surprise that ferritin is expressed in every cell type thus far studied (Worwood, 1990). Iron is essential for cellular functions such as oxygen transport, electron transfer, nitrogen fixation, DNA synthesis, and the production of haemoproteins like haemoglobin and myoglobin (Ponka et al., 1998). However, not all cell types harness iron for the same purposes or to the same extent and therefore the role of ferritin in the management of intracellular iron differs between the various types of cells. Ferritin can play a role in specialized functions, e.g. recycling of iron in macrophages and short- and long-term storage of iron as in hepatocytes, as well as in intracellular housekeeping functions where it provides a reserve for cytochromes, nitrogenases, ribo-nucleotide reductases, haemoglobin, and myoglobin (Theil, 1990). Perhaps equally important to its function in the storage and release of iron is the role that ferritin plays in the protection of cells against the deleterious effects of iron. Iron exists in two readily interconvertible redox states and, at physiological $\mathrm{pH}$ and oxygen tension, $\mathrm{Fe}^{2+}$ is readily oxidized to $\mathrm{Fe}^{3+}$, followed by the hydrolysis of $\mathrm{Fe}^{3+}$ and the formation of insoluble ferric hydroxide and oxyhydroxide polymers (Finch 
et al., 1984; Ponka et al., 1998). In addition, $\mathrm{Fe}^{2+}$ can catalyse the production of harmful oxygen radicals in the Haber - Weiss reaction resulting in peroxidative damage to cellular structures (Ponka et al., 1998, Powell, 1998). Within cells, iron probably exists in a low molecular weight, redox-active form only for short periods-mainly within the lysosomes. Lysosomes are therefore particularly vulnerable to oxidative stress and may burst due to intralysosomal Fenton-type chemistry with ensuing peroxidative destabilization of lysoso-mal membranes. This could result in leaky lysosomes and the induction of cellular damage, or even apoptotic or necrotic death due to the release of a range of powerful hydrolytic enzymes into the cytosol (Persson et al., 2001). By sequestering large amounts of iron as a soluble, nontoxic ferrihydrite mineral within the confines of the ferritin molecule, ferritin protects the cell against insoluble ferric oxide and oxyhydroxide formation, as well as against the production of oxygen radicals (Ford et al., 1984; Torti \& Torti, 2002).

Ferritin is widely distributed in cells and is found in the cytosol, nucleus, mitochondria and lysosomes and appears in plasma as a result of cellular secretion. This specific distribution enables ferritin to supply the particular enzymes and other proteins with appropriate amounts of iron, and, equally important, places ferritin in close proximity to sites where large amounts of iron are metabolized. Ferritin is actively transported into the nucleus to provide, amongst others, ribonucleotide reductase with iron and to protect DNA from oxidative damage as a result of inappropriate oxygen radical production due to surplus amounts of iron (Thompson et al., 2002). A specific type of ferritin is also found in mitochondria. Mitochondria is confronted with large amounts of metabolically active iron and although most cell types contain only very small amounts of a mito-chondrial ferritin, in certain conditions, a specific ferritin is translocated to the mitochondrium to sequester unwanted amounts of iron (Levi \& Arosio, 2004). The regulation of ferritin distribution in different parts of the cytosol and in cellular organelles is controlled, in part, by the various mechanisms involved in the uptake of ferritin by the cellular organelles. Furthermore, ferritin binds to microtu-bules and this interaction cannot only contribute to transport of ferritin to specific sites and organelles within the cell, but also to secretion of ferritin from the cell. Depolymerization of microtubules increase ferritin secretion and support the probable role of microtubules in regulating the intracellular concentration, distribution and release of ferritin under different physiological circumstances (Hasan et al., 2005).

\section{Iron, other iron-regulatory proteins and ferritin}

Humans contain 2 - 5 grams of iron, of which about two-thirds is present in the red blood cells as haemoglobin and about $15-20 \%$ in storage form as ferritin or haemosiderin. Ferritin is the intracellular protein responsible for normal iron storage whereas haemosiderin is a degradation product of ferritin, which is prominent during conditions of iron overload. The remainder of body iron is found mainly in muscle myoglobin (8\%) and in iron-containing enzymes (Brittenham, 1994). Only about $1 \mathrm{mg}$ of iron is absorbed and lost daily, mostly due to cell desquamation (Ponka et al., 1998), and an efficient mechanism exists for the shuttling of iron between iron absorption or storage sites (including sites for dismantling of spent iron-containing cells such as red blood cells), and sites of biosynthesis of ironcontaining proteins (Siegenberg et al., 1990). Trans-ferrin is the major transport protein responsible for this internal shuttling of iron. About $3 \mathrm{mg}$ of iron is found in association with transferrin at any one time and the daily exchange of iron by plasma transferrin is about $30 \mathrm{mg}$ (Ponka et al., 1998). Iron is chelated by transferrin at the cell membrane of the iron-donor cell and the transferrin is subsequently 
bound by a transferrin receptor on the membrane of the iron-acceptor cell (Brittenham, 1994). The transferrin- receptor complex is then internalized by the cell enclosed within an endocytic vesicle where iron is released from transferrin by a process that involves endosomal acidification. The resultant iron-free apotransferrin remains attached to the receptor in the endosome, and is returned to the cell surface where the apotransferrin is released from the cell (Ponka et al., 1998). Cells contain a pool of chelatable or transit iron known as the labile iron pool bound to low molecular weight intracellular iron transport compounds, and it is thought that the endosomal iron released from transferrin transits this pool of iron, whereupon iron enters functional compartments, or is stored in ferritin (Jacobs, 1977; Thomson et al., 1999). Since the labile pool of iron contains the metabolically and catalytically reactive iron (Piñero et al., 2000), the magnitude of the labile pool of iron is maintained by sophisticated control mechanisms that regulate cellular iron uptake and storage in a coordinated manner (Ponka et al., 1998). This is achieved by, amongst others, the coordinated regulation of the expression of the proteins involved in iron homeostasis such as transferrin, transferrin receptor and ferritin. An increase in the intracellular free iron will, for instance, result in up-regulation of ferritin (increase in efficiency of iron sequestration) and down-regulation of transferrin and transferrin receptor expression (decrease in iron acquisition potential), whereas a decrease in intracellular free iron will result in the opposite (Piñero et al., 2000; Ponka et al., 1998). This co-ordinated but divergent regulation of the expression of these proteins is governed by a single protein namely the iron-responsive protein (IRP), which can bind to iron-responsive elements on the mRNA of the iron homeostasis proteins. This will result in the posttranscriptional regulation of the mRNA of the proteins regulating iron uptake and storage (Piñero et al., 2000; Thomson et al., 1999).

\section{Structure of ferritin}

Ferritin, like some of the other proteins involved in the regulation of iron homeostasis in the body, including transferrin and lactoferrin, can serve either as an iron donor or iron acceptor (Levay \& Viljoen, 1995). However, unlike transferrin and lactoferrin, ferritin is capable of accepting, storing and donating vast amounts of iron. These abilities of ferritin are all a function of the structure of ferritin-especially that of the ferritin protein shell. Ferritin is a protein with a molecular weight of 450000 daltons (Theil, 1990) and consists of an outer three-dimensional protein shell enclosing an $80 \AA$ diameter inner cavity (Harrison \& Arosio, 1996). In this inner cavity ferritin is capable of sequestering variable amounts of $\mathrm{Fe}^{3+}$-atoms as a ferrihydrite mineral. When fully saturated, ferritin can store up to $4500 \mathrm{Fe}^{3+}$-atoms, but the usual amount is closer to $2000 \mathrm{Fe}^{3+}$-atoms (Ford et al., 1984; Harrison \& Arosio, 1996).

\section{Structure of the ferritin protein shell}

The outer three-dimensional protein shell contains a total of 24 protein subunits arranged symmetrically (Ford et al., 1984; Harrison \& Arosio, 1996). Two types of protein subunits exist, the H-subunit and the L-subunit. The H-subunit (21 kDa) contains 178 amino acids while the L-subunit (19 kDa) contains 174 amino acids (Ponka et al., 1998; Worwood, 1990). Each subunit is folded into four long a-helices (A, B, C, D), with a long loop between C and D, and a fifth short helix (E) at the C-terminal (Harrison \& Arosio, 1996). Each subunit is roughly cylindrical $(5.5 \mathrm{~nm}$ long and $2.7 \mathrm{~nm}$ wide) (Worwood, 1990). For the Lsubunit the amino acid arrangement into the various $\alpha$-helices is as follows: long $\alpha$-helix $A$ (amino acid residues 10 - 39), long $\alpha$-helix $B$ (amino acid residues $45-72$ ), long $\alpha$-helix $C$ (amino acid residues 92 - 120), long $\alpha$-helix $D$ (amino acid residues 124 - 155) and short $\alpha$-helix $E$ (amino acid residues 160 - 
169) (Ford et al., 1984). The four long a-helices are aligned parallel to one another and are tightly packed into a cylindrical subunit bundle (Ford et al., 1984; Worwood, 1990), thus forming the main subunit axis. Between the four long $\alpha$-helices the inter-helical contact region extends over a length of $35 \AA$ (Ford et al., 1984), while the longest helix, i.e. the $\alpha$-helix $D$, protrudes beyond this main interhelical contact region and folds sharply back so that the $\alpha$-helix $E$ lies at an angle roughly 60 degrees to the main axis of the subunit (Ford et al., 1984; Harrison \& Arosio, 1996). The other feature of the subunit, the long loop $L$ (amino acid residues $73-91$ ), joins the C-terminus of $\alpha$-helix $B$ to the $N$ terminus of $\alpha$-helix $C$ (Ford et al., 1984). Due to the inter-helical contacts and the arrangement of the subunit in the protein shell, the a-helices $B$ and $D$ have one face towards the inside of the ferritin protein shell, the $\alpha$-helices $A$ and $C$ have one face each towards the outside of the shell, and the loop $L$ is displayed on the outermost surface of the ferritin protein shell (Ford et al., 1984). This arrangement determines the types of amino acids situated on the inner face and the outer face of the subunit and therefore the subsequent intra-subunit and inter-subunit interactions. The secondary structure of the $\mathrm{H}$ subunit is very similar to that of the L-subunit, despite the fact that they share only $55 \%$ amino acid sequence homology (Worwood, 1990).

Intra-subunit and inter-subunit amino acid side-chain interactions of the ferritin protein shell. Highly conserved amino acid residues are involved in intra-subunit and inter-subunit interactions (Boyd et al., 1985; Theil, 1990; Worwood, 1990). The different types of intra-subunit and inter-subunit amino acid side-chain interactions that are important for ferritin folding and stability include hydrogen bonds, salt-bridges and hydrophobic interactions (Theil, 1990). The contributions of these types of interactions to the folding and stability of the $\mathrm{H}$ - and L-subunits differ significantly between the two types of subunits. The intrasubunit hydrogen bonds are about $50 \%$ more abundant in the $\mathrm{H}$-subunit than in the L-subunit, whereas the salt bridges are more important in the stabilization of the L-subunit and accounts for about $30 \%$ of the stabilization energy of the L-subunit (Martsev et al., 1998). Due to the large number of intra- and inter-subunit salt bridges the ferritin molecule is highly stable to thermal and chemical denaturation (Harrison \& Arosio, 1996). In addition, the differences in intra-subunit interactions between the $\mathrm{H}$ subunit and L-subunit result in a linear increase in the resistance to denaturation, with L-subunit homopolymers and heteropolymers containing a high L-subunit proportion significantly more resistant than H-subunit homopolymers (Martsev et al., 1998; Wade et al., 1991). One important difference in intra-chain interactions that contributes to the L-subunits being more stable than the $\mathrm{H}$-subunits is the salt-bridge lysine 62-glutamic acid 107 in the L-subunit which replaces the ferroxidase centre of the $\mathrm{H}$ subunit (Wade et al., 1991). However, these differences in intra-chain interactions between the $\mathrm{H}$ subunit and L-subunit appear to be largely masked by the presence of strong inter-subunit contacts in assembled molecules consisting of a combination of $\mathrm{H}$ - and L-subunits (Martsev et al., 1998). The interactions between subunits responsible for ferritin assembly involve about $50 \%$ of the subunit surface and most of the inter-subunit contacts are conserved in $\mathrm{H}$ - and L-subunits. The first intersubunit interaction to take place in the assemblage of the ferritin protein shell is the formation of interactions along the main subunit axis between two subunits creating a dimer pair (Theil, 1990). One face of the subunit contains hydrophobic residues from a-helix A (valine 20, leucine 24, tyrosine 28, leucine 31) and loop $L$ (phenylalanine 78, leucine 81, proline 84). By interaction with an equivalent region of a second subunit this hydrophobic patch of some $22 \AA$ in length is buried from solvent (Ford et al., 1984). 
Another hydrophobic region on the subunit surface is that comprising one face of a-helix $E$ (leucine 154 , leucine 161 , tyrosine 164 , leucine 165 , leucine 169) that will also be buried from solvent upon subunit interactions. There are a large number of inter-subunit interactions that form regions of marked hydrophobicity and other regions where polar interactions predominate (Ford et al., 1984). If these hydrophobic residues are to be partially buried from solvent then further assembly of dimers must occur. Since the assembly of ferritin consisting of 24 subunits results in the complete concealment of all hydrophobic patches (Ford et al., 1984), the formation of such a molecule is very favourable.

Channels present in the ferritin protein shell. For either mineralization or demineralization of the iron core to occur it is important that substances such as $\mathrm{Fe}^{2+} / \mathrm{Fe}^{3+}$, oxidants, reductants and chelators can gain access to the interior of the ferritin molecule. In order for these molecules to gain entrance to the interior of the protein shell the ferritin protein shell contains two main types of channels with strikingly different physical properties. The first type of channel comprises six hydrophobic channels with fourfold symmetry (12 $\AA$ long and $3-4 \AA$ wide), which are lined by 12 leucine side-chains in the L-subunit and 8 leucine plus 4 histidine side-chains in the $\mathrm{H}$-subunit belonging to the $\alpha$-helix $\mathrm{D}$. The second type of channel includes eight hydrophilic channels with threefold symmetry ( $3-4 \AA$ wide), each lined by six carboxyl groups, three aspartate residues (on the cavity side of the shell) and three glutamate residues (towards the outside of the molecule) belonging to the a-helix E (Chiancone \& Stefanini, 1984; Ford et al., 1984; Harrison \& Arosio, 1996; Levi et al., 1989). The carboxylate groups of the hydrophilic threefold channels are essential for rapid iron transport across the protein shell (Bou-Abdallah et al., 2002). The hydrophobic character of the six hydrophobic channels argues against a possible role for these channels in the transport of $\mathrm{Fe}^{2+} / \mathrm{Fe}^{3+}$-ions into the interior of the ferritin molecule. These fourfold hydrophobic channels are found to be impermeable to all cations with the possible exception of protons. It is suggested that these fourfold channels facilitate proton transfer in and out of ferritin in order to maintain electroneutrality during iron deposition (Takahashi \& Kuyucak, 2003). However, the substitution of leucine for histidine in the $\mathrm{H}$-subunit may confer iron transfer properties to the hydrophobic channel of the $\mathrm{H}$-subunit since histidine has a strong affinity for iron (Boyd et al., 1985). The hydrophilic channels are the most likely routes of iron entry into the protein shell and are probably functional in both the $\mathrm{H}$-subunit and the L-subunit. This is indicated by a high degree of conservation of the three glutamates and three aspartates in both subunits (Chasteen \& Harrison, 1999). Furthermore, alteration of residues of the hydrophobic channels has little effect on the rate and specificity of the reaction, whereas modifications of the carboxyl groups lining the hydrophilic channels reduce the rate of iron uptake by about twofold (Levi et al., 1996). The hydrophilic channel is funnel-shaped, broadening out towards the outside surface to give a wide hydrophilic region (Ford et al., 1984; Levi et al., 1996). The hydrophilic regions at the outside surface of the hydrophilic channels contain negative charges surrounded by patches of positive charges creating electrostatic fields in order to direct $\mathrm{Fe}^{2+}$ ions toward the channel entrance (Chasteen \& Harrison, 1999). Once iron has been directed to the opening of the hydrophilic channel, it is bound to hydrophilic residues located at the outer and inner openings of the channels (Chasteen, 1998). These residues include cysteine 130 and histidine 118, both of which face the outer opening of the hydrophilic channel (Chasteen, 1998), and aspartic acid 131 and glutamic acid 134 in the narrowest part of the channel (Levi et al., 1996; Theil, 1990). Aside from the hydrophobic and hydrophilic channels present in the ferritin protein shell, an $\mathrm{H}$-subunit specific channel exists that connects the ferroxidase site in the centre of the $\mathrm{H}$-subunit to the outer protein surface (Boyd et al., 1985). Although transfer of iron through this channel is in general less efficient, the 
transfer of $\mathrm{Fe}^{3+}$-ions to the outside of ferritin may become important in certain conditions.

The ferroxidase catalytic centre of the $\mathrm{H}$-subunit of the ferritin protein shell. The first step in the iron sequestration process by ferritin involves the oxidation of $\mathrm{Fe}^{2+}$ to $\mathrm{Fe}^{3+}$ by oxygen and is facilitated by the ferroxidase centre contained in the $\mathrm{H}$-subunit (Chasteen, 1998). This ferroxidase centre comprises various amino acid side-chains as important iron ligands in the multi-step oxidation of $\mathrm{Fe}^{2+}$ to $\mathrm{Fe}^{3+}$ and includes a cluster of hydrophilic amino acid residues (glutamic acid 27, glutamic acid 61, glutamic acid 62, histidine 65 and glutamic acid 107) which are embedded within each of the four a-helix bundles comprising the subunit (Levi et al., 1992; Santambrogio et al., 1996; Wade et al., 1991). This ferroxidase centre is present in the H-subunit, but absent in the L-subunit (Wade et al., 1991). The Lsubunit's potential ferroxidase activity is lost (Levi et al., 1992) due to amino acid changes including glutamic acid 62 to lysine and histidine 65 to glycine, formation of a salt-bridge between lysine 62 and glutamic acid 107 (Lawson et al., 1989) and swinging of glutamic acid 61 into a position facing the cavity (Chasteen, 1998).

The nucleation site of the L-subunit on the inner iron/ protein interface of the ferritin protein shell. The second step in the iron sequestration process by ferritin involves the formation of $\mathrm{Fe}^{3+}$-nuclei and the subsequent growth of an iron core. In order for ferritin to support $\mathrm{Fe}^{3+}$-nuclei formation and the growth of the iron mineral, ferritin must contain the $\mathrm{Fe}^{3+}$-atoms in the inner cavity of the protein shell and stabilize subsequently incoming $\mathrm{Fe}^{3+}$-atoms on the growing iron core. This is accomplished by amino acid side-chain ligands present on the inner surface of the ferritin protein shell. Binding of $\mathrm{Fe}^{3+}$ to these ligands supports $\mathrm{Fe}^{3+}$-nuclei formation, as well as the subsequent growth of the iron core. This results in the contact of the ferritin protein shell with the iron core at several points on the inner surface, forming an iron/protein interface. These iron/protein interfaces, which define the sites of core nucleation, probably exist where the protein subunit dimers interact (Theil, 1990). In contrast to the first step in iron sequestration, i.e. oxidation of iron, which is accomplished mainly by the $\mathrm{H}$-subunits, this second step, i.e. $\mathrm{Fe}^{3+}$-nuclei formation and the growth of the iron-core is mainly a function of the Lsubunits, which supply the appropriate amino acid side-chains. These amino acid side-chains act as ligands for the initially formed $\mathrm{Fe}^{3+}$ or as negatively charged domains that lower the activation energy of iron-core formation (Wade et al., 1991). The reason that the $\mathrm{H}$-subunits are less efficient in nucleation and iron-core formation is that only seven of the hydrophilic amino acid side-chains in L-subunits that line the inner surface, and which are not involved in the formation of salt bridges or hydrogen bonds but thought to bind iron, are conserved in $\mathrm{H}$-subunits. Amino acids important in nuclei formation and growth of the iron core include histidine 49 , arginine 52 , glutamic acid 53, glutamic acid 56 , glutamic acid 57 , arginine 59, glutamic acid 60, glutamic acid 61, arginine 64 and lysine 67 on a-helix B, with glutamic acid 136, lysine 139 and lysine 142 on $\alpha$-helix D, as well as 3 residues at the C-terminus, i.e. Iysine 172, histidine 173 and aspartic acid 174. The differences in amino acid side-chains between $\mathrm{H}$ - and Lsubunits result in the loss of negative charges in the $\mathrm{H}$-subunit on the inner iron/protein interface so that $\mathrm{H}$-subunits have a lower ability to nucleate iron (Boyd et al., 1985; Ford et al., 1984; Wade et al., 1991). A cluster of three L-subunit glutamates has specifically been implicated in $\mathrm{Fe}^{3+}$-nuclei formation. This cluster of glutamates, i.e. glutamic acid 57, glutamic acid 60, and glutamic acid 61, form a region of negativity for the binding of $\mathrm{Fe}^{3+}$. In the $\mathrm{H}$-subunit glutamic acid 57 and glutamic acid 60 are substituted for histidine and glutamic acid 61 is involved in the ferroxidase centre of the $\mathrm{H}$-subunit. It is suggested that glutamic acid 61 could also play a role in the nucleation of $\mathrm{Fe}^{3+}$ after oxidation of $\mathrm{Fe}^{2+}$. 
However, this putative nucleation site, involving glutamic acid 61, glutamic acid 64 and glutamic acid 67, does not play a role in nucleation and growth of the iron core (Bou-Abdallah et al., 2004). In the Lsubunit glutamic acid 61 is swung into a position on the inner cavity surface in proximity to glutamic acid 57 and glutamic acid 60 to participate in this cluster of negative charges responsible for the greater efficiency of L-subunits in iron-core nucleation (Levi et al., 1992; Levi et al., 1994).

\section{The iron mineral}

The iron mineral is enclosed in a cavity by a protein shell and contains different types of environments in which the $\mathrm{Fe}^{3+}$-ion is located. These different types of environments include:

1. Iron atoms located at nucleation sites - these $\mathrm{Fe}^{3+}$-ions are co-ordinated by amino acid side chain ligands from the inner protein surface and inorganic bonds from the mineral surface (Powell, 1998).

2. Iron atoms at the surface of the mineral-these $\mathrm{Fe}^{3+}$-ions are connected to the bulk mineral, as well as to the $\mathrm{Fe}^{3+}$-ions within the nucleation sites in the protein shell through inorganic oxide/ hydroxide linkages and there may be additional linkages to the $\mathrm{Fe}^{3+}$-ions of the shell through dinucleating amino acid side-chain ligands (Powell, 1998).

3. Iron atoms which are in environments corresponding to those of the bulk mineral connected through inorganic oxide/hydroxide linkages, where the $\mathrm{Fe}^{3+}$-ions are located in the interstices between two hexagonally closely packed layers of oxygen (Wixom et al., 1980; Worwood, 1982). The $\mathrm{Fe}^{3+}$-ions appear to be in predominantly octahedral environments but up to one-third of the $\mathrm{Fe}^{3+}$-ions are in tetrahedral sites, with an average of six oxygen atoms at a distance of approximately $2 \AA$. This, more or less, corresponds to the structure for ferrihydrite (Chasteen \& Harrison, 1999; Ford et al., 1984; Powell, 1998).

The iron core may differ between ferritin molecules, as well as within the same ferritin molecule, and can contain single or multiple crystallites and amorphous regions (Chasteen \& Harrison, 1999). One or more of such electron-dense crystallites are anchored to the inner surface of the protein shell (Wixom et al., 1980). The average diameter of the iron cores range from 2.5 to $9 \mathrm{~nm}$ (Chasteen \& Harrison, 1999). The formation of a single crystallite approaching the inner diameter of the protein shell or the formation of various smaller crystallites depends on the availability of $\mathrm{Fe}^{2+}-/ \mathrm{Fe}^{3+}$-ions during the later phases of mineral growth after nucleation has occurred (Theil, 1990). Striking features of the iron cores are their variable phosphate contents (Chasteen \& Harrison, 1999; Harrison \& Arosio, 1996). Phosphate ions are found on the surface of the iron cores where they replace some of the surface hydroxyl groups (Ford et al., 1984). However, recent observations indicate that phosphate can also be found throughout the iron core, that cores can have ordered and disordered regions, and that the disorder increases when phosphate increases (Theil, 1990). In vivo the phosphate contents of ferritin iron cores appear to be in dynamic equilibrium with cell phosphate (Ford et al., 1984) and it has long been suggested that phosphate plays a role in iron home-ostasis (Powell, 1998). This assumption has recently been supported by the fact that phosphate can stimulate the rate of iron uptake by providing binding sites on the mineral surface for incoming iron atoms and as such may play a role in the oxidation of $\mathrm{Fe}^{2+}$ on the mineral surface (Polanams et al., 2005). 


\section{Mechanism of iron sequestration and release: The role of the ferritin protein shell in iron mineralization and demineralization}

Ferritin concentrates iron in cells by directing the formation of a ferrihydrite mineral in the hollow cavity enclosed by the ferritin protein shell. This results in effective cellular iron concentrations of more than $10^{11}$ times the solubility of the $\mathrm{Fe}^{3+}$-ion (Takagi et al., 1998). In times of iron need ferritin releases iron by demineralization of the iron core. The exact steps involved in iron release are not completely known, but iron release involves the reduction of $\mathrm{Fe}^{3+}$ to $\mathrm{Fe}^{2+}$. The rates of the processes involved in iron mineralization and demineralization are controlled by the protein shell (Theil, 1990) —-this by influencing the local $\mathrm{pH}$ and redox potentials (Powell, 1998). The formation of the ferrihydrite mineral by ferritin is a multi-step process governed by the protein shell. Iron enters the ferritin cavity by passage through the channels situated in the protein shell facilitated by the presence of local iron binding sites (Harrison \& Arosio, 1996). Upon entering the protein shell the iron is oxidized followed by hydrolysation, nucleation and iron core growth (Ford et al., 1984). Each of these steps contributes to the formation of a ferrihydrite mineral core from soluble $\mathrm{Fe}^{2+}$-ions.

\section{Oxidation of iron}

Oxidation of $\mathrm{Fe}^{2+}$ by the ferroxidase centre of the $\mathrm{H}$-subunit. Oxidation of $\mathrm{Fe}^{2+}$ is an obligatory first step in order for an iron atom to finally be deposited in the cavity of ferritin. The H-subunit's ferroxidase centre, formed by various amino acid side-chains, enzyma-tically oxidizes $\mathrm{Fe}^{2+}$ to $\mathrm{Fe}^{3+}$. Enzymatic oxidation of $\mathrm{Fe}^{2+}$ by the ferroxidase centre results in rates of iron oxidation several-fold faster than that which would occur during auto-oxidation of iron. This faster rate of iron oxidation results from the proper placement of $\mathrm{Fe}^{2+}$ atoms by the ligands of the ferroxidase centre of the $\mathrm{H}$-subunit for subsequent oxidation by $\mathrm{O}_{2}$ (Cozzi et al., 2000). X-ray analysis has revealed three iron-binding sites per $\mathrm{H}$-subunit. Sites $\mathrm{A}$ and $\mathrm{B}$ (3.8 $\AA$ apart) form a di-iron site and include a common bridging carboxylic acid residue. Ligands of site $A$ also include one equivalent histidine and one glutamate glutamic acid 27 , whereas site $B$ has two carboxylate ligands in addition to the bridging carboxylate. These are glutamic acid 107 and glutamic acid 61 . The third site, i.e. site $C$, lies in the inner surface of the protein shell at a distance of $7 \AA$ from the di-iron site. The first step in $\mathrm{Fe}^{2+}$ oxidation involves the binding of incoming $\mathrm{Fe}^{2+}$ atoms with each of sites $A$ and $B$, followed by the formation of a $\mu$-oxo-bridge (Treffry et al., 1997). The affinity of site $A$ for $\mathrm{Fe}^{2+}$ is higher than the affinity of site $\mathrm{B}$, resulting in the occupation of site $\mathrm{A}$ by $\mathrm{Fe}^{2+}$ before site $\mathrm{B}$. Binding of $\mathrm{Fe}^{2+}$ to site $\mathrm{B}$ follows $\mathrm{O}_{2}$ binding and/or oxidation of the first $\mathrm{Fe}^{2+}$ (Bou-Abdallah et al., 2002). After about an hour of intermediate $\mu$-oxo -bridged dimer formation, this complex splits into highly mobile $\mathrm{Fe}^{3+}$-monomers that can move to the cavity for $\mathrm{Fe}^{3+}$ hydrolysis, nucleation and growth of the iron core (Cozzi et al., 2000; Santambrogio et al., 1996). An unusually short distance of $2.53 \AA$ between the two $\mathrm{Fe}^{2+}$ ions suggests the presence of a unique triply bridged structure requiring a small Fe-O-O angle. This geometry should favour decay of the peroxodiferric complex by the release of $\mu$-oxo or $\mu$ hydroxo diferric mineral precursors (Hwang et al., 2000; Liu \& Theil, 2004). This would result in freeing of the ferroxidase sites for binding of additional $\mathrm{Fe}^{2+}$ and the start of another round of $\mathrm{Fe}^{2+}$ oxidation (Chasteen, 1998). A by-product produced during the ferroxidase centre oxidation of $\mathrm{Fe}^{2+}$ is $\mathrm{H}_{2} \mathrm{O}_{2}$, which can result in the subsequent production of Fenton chemistry-derived radicals (Chasteen, 1998). 
Oxidation of $\mathrm{Fe}^{2+}$ on the surface of the growing iron core. During the initial stages of ferritin iron core mineralization, oxidation of $\mathrm{Fe}^{2+}$ takes place in the ferroxidase centres of the $\mathrm{H}$-subunits of the ferritin protein shell. Once the mineral attains a certain critical size, oxidation of $\mathrm{Fe}^{2+}$ can additionally, and perhaps preferentially, occur on the surface of the growing iron core (Chasteen, 1998; Ford et al., 1984; Powell, 1998). Therefore, the main function of the ferroxidase centre may be oxidation of sufficient iron from $\mathrm{Fe}^{2+}$ to $\mathrm{Fe}^{3+}$ for the initial nucleation events, and once these nuclei attained a sufficient size for oxidation to take place on the mineral surface, the $\mathrm{H}$-subunit's role as a ferroxidase is superseded by oxidation on the mineral surface (Lawson et al., 1989; Treffry et al., 1997).

\section{Hydrolysis and nucleation of the formed $\mathrm{Fe}^{3+}$}

The subsequent hydrolysis and nucleation of the generated $\mathrm{Fe}^{3+}$ is governed by the amino acid sidechains of the L-subunit (Chasteen, 1998). The highly mobile $\mathrm{Fe}^{3+}$-monomers are directed to the inner cavity and properly placed on the protein shell/ mineral interface by these ligands. The subsequent hydrolysis and nucleation involves the hydrolysis and aggregation of $\mathrm{Fe}^{3+}$-ions to form nuclei containing perhaps as few as four or five constituent $\mathrm{Fe}^{3+}$-ions resulting in the production of iron oxyhydroxides and oxides (Chasteen \& Harrison, 1999; Powell, 1998). Hydrolysis and nucleation of the $\mathrm{Fe}^{3+}$-ion is favoured since binding of $\mathrm{Fe}^{3+}$ to the ligands lowers the activation energy of nucleation (Harrison \& Arosio, 1996; Powell, 1998). Such nuclei can become the solid phase once some critical nucleus size has been reached and will sustain iron mineral growth from these sites (Powell, 1998). These initial sites of nuclei formation on the inner surface of the protein shell, involving specific amino acid sidechains, will maintain contact with the iron core (Powell, 1998). This interaction with the iron core seems to be a key factor in the stabilization of the crystal by providing a neutral container, or more likely, the interactions with negatively charged and neutral amino acid side-chains such as carboxylates, alkoxides, phenolates, and imidazoles provide the necessary charge compensation (Powell, 1998).

\section{Different iron oxidation kinetics and the formation of different reaction products by the ferroxidase centre oxidation of iron and oxidation of iron on the mineral surface}

Oxidation of $\mathrm{Fe}^{2+}$ by the ferroxidase centre and oxidation of $\mathrm{Fe}^{2+}$ on the mineral surface take place under different conditions. These processes have different iron oxidation kinetics and result in the formation of different reaction products (Levi et al., 1994). At low Fe ${ }^{2+}$ concentrations $\left(<50 \mathrm{Fe}^{2+}\right.$ atoms/ferritin molecule) oxidation of $\mathrm{Fe}^{2+}$ is catalysed by the ferroxidase centre and the reaction stoichiometry is as follows:

For the oxidation reaction:

$$
2 \mathrm{Fe}^{2+}+\mathrm{O}_{2}+2 \mathrm{H}^{+} \longrightarrow 2 \mathrm{Fe}^{3+}+\mathrm{H}_{2} \mathrm{O}_{2}
$$

For the subsequent hydrolysis reaction:

$$
2 \mathrm{Fe}^{3+}+4 \mathrm{H}_{2} \mathrm{O} \rightarrow 2 \mathrm{FeOOH} \text { core }+6 \mathrm{H}^{+}
$$

For the sum of the oxidation and hydrolysis reactions:

$$
2 \mathrm{Fe}^{2+}+\mathrm{O}_{2}+4 \mathrm{H}_{2} \mathrm{O} \rightarrow 2 \mathrm{FeOOH} \text { core }+\mathrm{H}_{2} \mathrm{O}_{2}+4 \mathrm{H}^{+}
$$


In the presence of higher $\mathrm{Fe}^{2+}$ concentrations (>250 $\mathrm{Fe}^{2+}$ atoms/ferritin molecule) the $\mathrm{H}$-subunit ferroxidase site becomes kinetically saturated and the size of the growing mineral reaches a size sufficient to sustain oxidation of $\mathrm{Fe}^{2+}$ on the mineral surface. This results in the changing of the dominant mechanism of iron oxidation from the ferroxidase centre to the mineral surface catalysed mechanism (Chasteen, 1998). The reaction stoichiometry changes to the following:

For the oxidation reaction:

$$
4 \mathrm{Fe}^{2+}+\mathrm{O}_{2}+4 \mathrm{H}^{+} \rightarrow \cdot 4 \mathrm{Fe}^{3+}+2 \mathrm{H}_{2} \mathrm{O}
$$

For the subsequent hydrolysis reaction:

$$
4 \mathrm{Fe}^{+}+8 \mathrm{H} 2 \mathrm{O} \rightarrow 4 \mathrm{FeOOH} \text { core }+12 \mathrm{H}^{+}
$$

For the sum of the oxidation and hydrolysis reactions:

$$
4 \mathrm{Fe}^{2+}+\mathrm{O}^{2}+6 \mathrm{H}_{2} \mathrm{O} \rightarrow 4 \mathrm{FeOOH} \text { core }+8 \mathrm{H}^{+}(\text {Chasteen 1998) }
$$

Such differences in iron oxidation kinetics by ferritin are displayed in cells under varying conditions. Under cellular conditions where low $\mathrm{Fe}^{+}$concentrations relative to the amount of apoferritin may be expected, the ferroxidase activity of $\mathrm{H}$-subunits is probably essential to initiate the formation of iron nuclei and for iron mineralization to proceed at a significant rate (Lawson et al., 1989). Autocatalytic $\mathrm{Fe}^{2+}$ oxidation on the surface of the growing iron mineral can only be significant once an initial iron core has been established (Lawson et al., 1989). However, it has certain advantages above the process that occurs in the ferroxidase centre of the $\mathrm{H}$-subunit. The first biological advantage is that the potentially toxic production of hydrogen peroxide by the oxidation reaction, that takes place in the ferroxidase centre, is replaced by the harmless reduction of di-oxygen to water via the oxidation reaction on the mineral surface (Chasteen, 1998; Treffry etal., 1997). As ferritin lacks catalase activity, the $\mathrm{H}_{2} \mathrm{O}_{2}$ produced during the ferroxidase centre catalysed oxidation of iron results in some degradation of the ferritin protein shell. In effect, the protein itself acts as an anti-oxidant (Chasteen, 1998). Another advantage of such a change in iron kinetics is that it enhances the ability of ferritin to increase the rate of iron oxidation when challenged with a large amount of $\mathrm{Fe}^{2+}$-ions. The ferroxidase centre can be reutilized for another round of $\mathrm{Fe}^{2+}$ oxidation only once the generated $\mathrm{Fe}^{3+}$-ion moves from the ferroxidase centre into the iron storage cavity for subsequent nucleation. However, this rate of regeneration may be too slow to process a large number of $\mathrm{Fe}^{2+}$-ions added at once, and under such conditions, oxidation on the mineral surface may occur even during earlier stages. These different oxidation abilities of ferritin to mineralize iron result in the formation of crystallites of different sizes. Under conditions favouring fast iron accumulation the 'ferrihydrite' produced has a relatively large crystallite size and a nearly all-or-none distribution within ferritin molecules since the mineralization process will be favoured by oxidation of $\mathrm{Fe}^{2+}$ on the mineral surface (Ford et al., 1984) and the rate of iron deposition will be governed by the surface area of the iron mineral (Worwood, 1982). However, under conditions of low $\mathrm{Fe}^{2+}$ concentrations oxidation of $\mathrm{Fe}^{2+}$ will take place on different ferroxidase centres resulting in the formation of many small crystallites (Ford et al., 1984). 


\section{Migration of iron between ferritin molecules}

Iron can migrate between ferritin molecules (Wade et al., 1991), either as $\mathrm{Fe}^{2+}$ or as $\mathrm{Fe}^{3+}$. Migration of iron between ferritin molecules occurs if the movement of $\mathrm{Fe}^{2+} / \mathrm{Fe}^{3+}$ to the next ferritin molecule results in favouring of the oxidation or hydrolysis/ nucleation processes. Oxidation of $\mathrm{Fe}^{2+}$ results in the generation of highly mobile $\mathrm{Fe}^{3+}$-ions, which subsequently have to be incorporated into a growing mineral crystal by a hydrolysis/nucleation process. Since L-subunits promote hydrolysis and nucleation of $\mathrm{Fe}^{3+}$ by binding of $\mathrm{Fe}^{3+}$ to specific L-subunit ligands, insufficient quantities of the L-subunit present in the ferritin molecule can result in the migration of $\mathrm{Fe}^{3+}$ to a ferritin molecule with sufficient quantities of L-subunit (Levi et al., 1992). The generated $\mathrm{Fe}^{3+}$ would move to the outer surface of the ferritin protein shell via an $\mathrm{H}$-subunit specific channel linking the ferroxidase centres with the outer surface of the protein shell (Levi et al., 1996). This results in competition between ferritin molecules for iron and a tendency towards all-or-none distribution (Ford et al., 1984; Harrison \& Arosio, 1996; Wade et al., 1991).

\section{Non-specific $\mathrm{Fe}^{3+}$ hydrolysis on the outer surface of the ferritin protein shell}

When insufficient quantities of L-subunits exist for the entrapment of $\mathrm{Fe}^{3+}$ in the inner cavity $\mathrm{Fe}^{3+}$ can move to the outer surface of the protein shell where non-specific hydrolysis of $\mathrm{Fe}^{3+}$ can take place (Levi et al., 1994). Non-specific iron hydrolysis on the outer surface of the ferritin molecule can result in protein aggregation and precipitation (Levi et al., 1994). Spontaneous aerobic iron hydrolysis such as that which occurs on the outer surface of the ferritin protein shell appears to be caused by the formation of transient mono-nuclear hydrated $\mathrm{Fe}^{3+}$-ions which have a strong tendency to aggregate and coagulate (Levi et al., 1994).

\section{The cooperative roles of the H-subunit and L-subunit of the ferritin protein shell in iron mineralization}

Since the $\mathrm{H}$-subunit and the L-subunit of the protein shell have separate roles in the mineralization process of iron by ferritin and the specific properties of the two subunits are complementary and act synergisti-cally, co-operation between these subunits is paramount for the efficient mineralization of iron by ferritin. The ratio of $\mathrm{H}$-subunits to $\mathrm{L}$-subunits is therefore important. While oxidation of $\mathrm{Fe}^{2+}$ by the ferroxidase centre of the $\mathrm{H}$-subunit accelerates the supply of $\mathrm{Fe}^{3+}$ the subsequent hydrolysis and nucleation processes are driven by the L-subunit (Chasteen \& Harrison, 1999; Levi et al., 1992). If insufficient quantities of the L-subunit are assembled into the protein shell non-specific hydrolysis of $\mathrm{Fe}^{3+}$ can take place on the outside of the protein shell. This may lead to aggregation and precipitation of ferritin molecules (Levi et al., 1994). Although very few $\mathrm{H}$-subunits are necessary to initiate the process of iron oxidation, a deficit in $\mathrm{H}$-subunits can result in poor iron sequestration abilities. Furthermore, $\mathrm{H}$ and L-subunits can act co-operatively when in separate molecules (Levi et al., 1992).

The co-operative roles of the subunits of ferritin in the mineralization process of iron have been demonstrated by the formation of recombinant $\mathrm{H}$-subunit or L-subunit homopolymers and recombinant $\mathrm{H}$-subunit/L-subunit heteropolymers. In vitro experiments involving recombinant ferritin molecules showed that:

a. Both the H-subunit and L-subunit homopolymers have the capacity to incorporate iron. However, since the recombinant L-subunit homopolymer relies on auto-oxidation of iron for the initial 
generation of $\mathrm{Fe}^{3+}$ the recombi- nant $\mathrm{H}$-subunit homopolymer exhibits iron uptake and ferroxidase kinetics several-fold faster than the recombinant L-subunit homo-polymer (Levi et al., 1994; Wade et al., 1991; Worwood, 1990).

b. The rate of iron uptake increases with an increase in the $\mathrm{H}$-subunit proportion from 0 to $35 \%$ of the ferritin molecule. A plateau is, however, reached with further increase in the $\mathrm{H}$-subunit content (Wade et al., 1991).

c. Ferritin $\mathrm{H}$-subunit homopolymers have a low ability to nucleate the generated $\mathrm{Fe}^{3+}$ and therefore take up and release iron faster since the generated $\mathrm{Fe}^{3+}$ is not tightly bound in an iron mineral (Boyd et al., 1985).

d. Ferritin L-subunit homopolymers, when supplied with $\mathrm{Fe}^{3+}$ are more efficient in promoting iron mineralization than the corresponding $\mathrm{H}$-subunit homopolymers (Levi et al., 1994).

e. H-subunit/L-subunit heteropolymers are more efficient in taking up iron than the parent homopolymers (Levi et al., 1994). A high synergism between the two subunits occurs in ferritins with low $\mathrm{H}$-subunit content $(10-30 \%)$ and high L-subunit content $(70-90 \%)$, a few ferroxidase centres are sufficient to promote fast iron oxidation, and many L-subunits are needed to reduce non-specific iron hydrolysis and facilitate iron mineralization (Levi et al., 1994).

f. L-subunit homopolymers can incorporate some of the iron oxidized by $\mathrm{H}$-subunit homopolymers (Levi et al., 1994).

g. The amount of soluble ferritin molecules increases sharply in heteropolymers with an L-subunit content higher than $70-80 \%$, thus preventing the non-specific iron hydrolysis on the outside of the protein shell and the subsequent protein aggregation/precipitation (Levi et al., 1994). h. Hsubunit/L-subunit heteropolymers with low $\mathrm{H}$-subunit content $(18-30 \%)$ incorporate 3 to 4 times more iron than $\mathrm{H}$-subunit homopolymers (Levi et al., 1994).

i. The most efficient heteropolymers for in vitro iron incorporation are structurally similar to the ferritins found in the tissues which accumulate iron, such as liver and spleen, which typically contain 80 95\% L-subunit, 5 - 20\% H-subunit. Other tissues with lower needs for iron storage may prefer ferritins with higher $\mathrm{H}$-subunit content which, having a higher ferroxidase activity, are probably more efficient for iron detoxification (Levi et al., 1992, 1994).

j. L-subunit homopolymers containing nuclei will develop at the expense of L-subunit homopoly-mers without nuclei by autocatalytic growth processes on the surface of the iron mineral (Wade et al., 1991).

The respective and synergistic roles of the $\mathrm{H}$-subunit and L-subunit of ferritin is also indicated in vivo, since in vivo $\mathrm{H}$-subunit homopolymers are much less efficient than the $\mathrm{H}$-subunit/L-subunit heteropolymers in taking up iron (Cozzi et al., 2000).

\section{The release of iron from ferritin}

Two mechanisms have been proposed for the release of iron from ferritin. Iron can be either released from the intact ferritin molecule or released upon the degradation of the ferritin molecule (Aisen, 1991; Deiss, 1983). However, the relative importance of iron release in vivo by the one or the other of these mechanisms is not known. Two processes are chemically feasible for removing iron from the intact ferritin molecule-the first process the reduction of $\mathrm{Fe}^{3+}$ to $\mathrm{Fe}^{2+}$ followed by chelation of $\mathrm{Fe}^{2+}$, and the second the direct chelation of $\mathrm{Fe}^{3+}$ (Harrison \& Arosio, 1996; Liu et al., 2003; Gálvez et al., 2005). The release of iron from ferritin by these two processes is accomplished with the aid of reductants and iron 
chelators that can cross the protein shell. Reductants and chelators gain access to the interior of the ferritin molecule through the threefold channels of the protein shell. It is suggested that the channels of the ferritin protein shell are dynamic and control the access of reductants and chelators, since reductants and chelators too large to pass through the channels can under certain conditions gain access to the interior of the ferritin molecule (Liu et al., 2003). Chaotropes can increase the access of reductants and chelators to the interior of ferritin by influencing the gating of the channel (Gálvez et al., 2005; Liu et al., 2003). Various reductants and chelators, including physiological and toxicological substances, can release iron from ferritin (Agrawal et al., 2001; Gálvez et al., 2005; Hynes \& Coinceanainn, 2002; Sánchez et al., 2005). With the first of the two processes that remove iron from intact ferritin, i.e. the process involving the reduction of $\mathrm{Fe}^{3+}$ to $\mathrm{Fe}^{2+}$, followed by chelation of $\mathrm{Fe}^{2+}$, the reductant has to gain access to the interior of the protein shell to reduce the $\mathrm{Fe}^{3+}$ to $\mathrm{Fe}^{2+}$. However, the formed $\mathrm{Fe}^{2+}$ will only leave the ferritin protein shell in the presence of a chelator (Jameson et al., 2004). With the second of the two processes, i.e. the direct chelation of $\mathrm{Fe}^{3+}$ where the $\mathrm{Fe}^{3+}$ is not reduced, $\mathrm{Fe}^{3+}$ leaves the ferritin protein shell as a $\mathrm{Fe}^{3+}$-complex. The hydrous ferric oxide cores can be reduced by one electron per iron atom accompanied by an uptake of two protons per electron from the surrounding medium (Watt et al., 1985). This is then followed by the chelation of $\mathrm{Fe}^{2+}$ and the transport to sites where $\mathrm{Fe}^{2+}$ is needed (Joshi \& Clauberg, 1988; Watt et al., 1985). Effective reducing agents for the release of iron from ferritin include flavins, cysteine, glutathione, ascorbic acid and superoxide (Ponka et al., 1998).

The initial rate of iron release shows a dependence on iron content, with maximum rate of release for relatively iron-poor molecules, which are one-third to one-half saturated with iron. It also depends on the surface area of the crystallite. This dependence resembles that for iron uptake and suggests a direct interaction between the surface of the iron core and the reducing agent (Chiancone \& Stefanini, 1984; Theil, 1990; Worwood, 1990). Furthermore, as iron atoms at the surface of the iron core could be expected to be more accessible to reducing agents than those in the interior, a last-in-first-out principle is obeyed (Worwood, 1990). It has also been suggested that the release of iron from the intact ferritin molecule is sensitive to changes in conserved amino acids near the outside of the ferritin channels which are likely to be involved in regulating the localised unfolding of the protein shell in order to open the channels and release the reduced iron (Jin et al., 2001).

\section{Isoferritins}

\section{Different $\mathrm{H}$-subunit/L-subunit compositions of the ferritin protein shell}

The multiple forms of ferritin have their molecular basis in the ratio of the two subunit types present, i.e. the H-subunit and the L-subunit (Chiancone \& Stefanini, 1984). The ferritin protein shell exists as heteropolymers of various combinations of these two types of subunits (Arosio et al., 1978)—a phenomenon that gives rise to the existence of isoferritins. As the roles of the H-subunit and L-subunit differ in the mineralization process, the subunit composition of ferritin will influence the metabolic properties of the assembled ferritin molecules (Harrison \& Arosio, 1996; Levi et al., 1994). H-subunit rich ferritins have been shown to accumulate and release iron faster than do L-subunit rich ferritins (Arosio et al., 1991; Chiancone \& Stefanini, 1984; Wagstaff et al., 1982; Worwood, 1990) and it is suggested that the $\mathrm{H}$-subunit rich ferritins permit more dynamic in-tracellular traffic of iron (Chiancone \& Stefanini, 1984; Speyer \& Fielding, 1979). L-subunit rich ferritins apparently contain more iron than 
those ferritins rich in $\mathrm{H}$-subunits (Bomford et al., 1981; Chiancone \& Stefanini, 1984) and there are indications that the L-subunit rich ferritins predominate in cell types that play a role in the storage of iron (Boyd et al., 1985; Chiancone \& Stefanini, 1984; Coccia et al., 1992; Powell et al., 1975). However, increases in ferritins rich in the $\mathrm{H}$-subunit have been shown to provide cells with increased resistance to $\mathrm{H}_{2} \mathrm{O}_{2}$ toxicity (Cozzi et al., 2000). It would further appear that a specific subunit composition may cater for iron storage, and that iron loading would increase the expression of the L-subunit whereupon these L-subunit rich isoferritins will sequester the bulk of the surplus iron (Bomford et al., 1981; Invernizzi et al., 1990). In general, L-subunit rich ferritins contain 1500 iron atoms or more whereas $\mathrm{H}$ subunit rich ferritins contain less than a 1000 iron atoms (Harrison \& Arosio, 1996). In situations of iron overload it may be advantageous to the cell to synthesize L-subunit rich ferritins, since these ferritins are not only able to store more iron but can also retain iron more firmly and turn over iron more slowly than H-subunit rich ferritins (White \& Munro, 1988). The assumed role that the L-subunit rich ferritins play in the sequestration of the surplus iron during iron overload is underlined by the fact that their concentration in liver, serum and cultured cells is related to iron levels, whereas the $\mathrm{H}$-subunit rich ferritins appear either to be non-affected (in liver) or negatively affected (in serum) by increases in iron concentrations (Ruggeri et al., 1984). Furthermore, upon iron supplementation of patients with functional iron deficiency in the presence of tissue iron overload there would appear to be a proportionately greater change in L-subunit rich ferritins than in $\mathrm{H}$-subunit rich ferritins (Ruggeri et al., 1984). Due to the H-subunit rich ferritin's more dynamic ability of iron uptake and release it would appear to be largely found in cells having high iron requirements for metabolic activities and a nonexistent role in iron storage (Cazzola et al., 1983). Cells with a high content of H-subunit rich ferritins include erythroid cells, heart cells, pancreatic cells, kidney cells, lymphocytes and monocytes (Jones et al., 1983; Worwood, 1982), whereas the L-subunit rich ferritins are found predominantly in liver and spleen-organs associated with long-term iron storage (Powell et al., 1975; Worwood, 1982). The H- to L-subunit ratio of a specific type of cell does not, however, remain constant and the proportion of the $\mathrm{H}$ and L-subunits present in the ferritin shell changes during differentiation and in various pathological states (Arosio et al., 1976; Boyd et al., 1985; Ponka et al., 1998; Theil, 1990).

The variations in the type of isoferritins present in erythroid cells are well studied. The presence of different isoferritins with different metabolic properties reflects the changing iron needs of the erythroid cell. The erythroid cells contain mainly $\mathrm{H}$-subunit rich ferritins, which play a major role in the intracellular transport and donation of iron for the active synthesis of heme (Coccia et al., 1992), particularly in immature erythroid cell precursors such as proerythroblasts and basophilic erythro-blasts (Invernizzi et al., 1990). However, when iron accumulates in erythroid tissue due either to an increase in the cellular uptake of iron or a decrease in iron usage for heme synthesis, the L-subunit rich ferritins seem to increase and to be closely related to the iron status of the cells (Cazzola et al., 1983; Invernizzi et al., 1990). The H-subunit/ L-subunit ferritin composition is reported to decrease with erythroblast maturation (Cazzola et al., 1983), with $\mathrm{H}$-subunit rich ferritin content higher in the early erythroblast fractions and decreasing with maturation. The content of L-subunit rich ferritin, apparently does not show such consistent changes with maturation (Hodgetts et al., 1986).

The ferritin present in reticuloendothelial cells (Invernizzi et al., 1990; Ruggeri et al., 1992) and other macrophage-like cells are predominantly L-subunit rich (Cheepsunthorn et al., 1998; Connor et al., 1994). An exception is the ferritin in human peripheral blood monocytes, which seems to be rich in $\mathrm{H}$ - 
subunits (Jones et al., 1983). However, in vitro macrophages, which originate from monocytes, would appear to develop an L-subunit predominance. This phenomenon is mainly associated with the loss of $\mathrm{H}$-subunits (Jones et al., 1983). At present, indications are that the addition of iron can cause an increase in both $\mathrm{H}$ - and $\mathrm{L}$-subunits despite the persistence of a very low $\mathrm{H}$-subunit/L-subunit ratio. The presence of mainly L-subunit rich ferritin is in keeping with the role of the reticuloendothelial cell/other macrophage-like cells in the scavenging of effete cells and the sequestration and storage of large amounts of iron. An interesting phenomenon is the fact that the same type of process may also occur in the brain. Microglia, a macrophage-like cell present in the brain (Cheepsunthorn et al., 1998; Connor et al., 1994), is responsible for the phagocytosis of cellular debris during axon remodeling and naturally occurring cell death in the developing brain (Cheepsunthorn et al., 1998). These cells contain predominantly L-subunit rich ferritins consistent with its role in long-term iron storage (Connor et al., 1994).

\section{The synthesis of ferritin}

The apoferritin molecule, consisting of $24 \mathrm{H}$ - and L-subunits, is assembled from a cytosolic pool of available $\mathrm{H}$ - and L-subunits. This cytosolic pool of free $\mathrm{H}$ - and L-subunits is maintained by the supply of $\mathrm{H}$ - and L-subunits upon translation of $\mathrm{H}$ - and L-subunit mRNA by free polyribosomes and the proper folding of the polypeptide chains. While the composition of $\mathrm{H}$ - and L-subunits in the ferritin molecule is determined by the $\mathrm{H}$ - and L-subunits available in this pool, the quantity and composition of the $\mathrm{H}$ - and L-subunits in this pool of available subunits is regulated at both the transcriptional and translational levels of expression of the ferritin $\mathrm{H}$ - and L-subunit genes.

\section{Assembly of ferritin from the pool of available $\mathrm{H}$ and L-subunits}

The 24-subunit ferritin protein shell is assembled in the cytosol from a pool of free, unassembled, or only partly assembled $\mathrm{H}$ - and L-subunits (Harrison \& Arosio, 1996). These H- and L-subunits are synthesized by free polyribosomes and a basal concentration of free $\mathrm{H}$ - and L-subunits is maintained in this cytosolic pool of subunits. When this concentration rises as a consequence of the synthesis of new $\mathrm{H}$ - and L-subunits by free polyribosomes, subunits will be assembled into apoferritin in the cytosol near the polyribosomes. Since $\mathrm{H}$ - and L-subunits have the same conformation and many identical or similar amino acids are involved in the inter-subunit contact regions between $\mathrm{H}$-subunit/ $\mathrm{H}$-subunit, $\mathrm{H}$ subunit/L-subunit or L-subunit/ L-subunit interactions, a complete range of subunit compositions of homopolymers and heteropolymers is possible (Harrison \& Arosio, 1996; Theil, 1990). However, homopolymers of ferritin consisting of either only $\mathrm{H}$-subunits or only L-subunits are poorly represented in cells, suggesting the existence of preferential interactions between $\mathrm{H}$ - and L-subunits. This is in agreement with cross-linking experiments showing a preferential formation of $\mathrm{H}$-subunit/L-subunit dimers (Santambrogio et al., 1993).

Iron is incorporated into apoferritin or iron-poor ferritin molecules only once the ferritin shell is completely assembled from the available $\mathrm{H}$ - and L-subunits (Harrison \& Arosio, 1996). This fraction of $\mathrm{H}$ - and L-subunits synthesized by free polyribosomes is destined for the intracellular sequestration of iron while a much smaller fraction of $\mathrm{H}$ - and L-subunits are synthesized by membrane-bound polyribosomes and once assembled the ferritin is secreted by the cell to the extracellular fluid (Worwood, 1982). 


\section{Regulation of the expression of the H-subunit and L-subunit genes of ferritin}

The $\mathrm{H}$ - and L-subunit genes of ferritin are expressed in most cells, but the concentration of the assembled ferritin can vary 1000-fold among different cell types (Theil, 1990). Furthermore, the composition of the $\mathrm{H}$ - and L-subunits in the ferritin molecule differs between different cell types, resulting in the cellular-dependent variation of isoferritin populations (Harrison \& Arosio, 1996). This is achieved by the regulation of the expression of the $\mathrm{H}$ - and L-subunit genes of ferritin. Different mechanisms of regulation exist including transcriptional, modulation of transcript stability, translational depending on the metabolically available iron concentration and trans-lational irrespective of the metabolically available iron concentration. The regulation of the transcription of the $\mathrm{H}$ - and L-subunit genes occurs mainly irrespective of the metabolically available iron concentration. However, there are indications that the transcription of the $\mathrm{H}$ - and L-subunit genes can be influenced by the metabolically available iron concentration in specific conditions (Theil, 1990; White \& Munro, 1988). The transcriptional regulatory mechanisms and stability of the mRNA determine the mRNA concentrations of the $\mathrm{H}$ - and L-subunits, whereas the translational regulatory mechanisms determine the magnitude of mRNA translation and the subsequent formation of the $\mathrm{H}$ - and L-subunits of ferritin. Therefore the relative proportion of $\mathrm{H}$ - and $\mathrm{L}$-subunits in the final ferritin molecules depends mostly on multiple transcriptional regulations (transcription or stability) that affect the respective proportion of $\mathrm{H}$ - and $\mathrm{L}$ subunit mRNA in the total pool of translatable ferritin mRNA, whereas the total amount of ferritin produced in the cells depends on the magnitude of translation of the $\mathrm{H}$ - and L-subunit mRNA (Ponka et al., 1998). Ferritin synthesis is stimulated during development, during cell differentiation, by proinflammatory cytokines, as well as by some hormones (Festa et al., 2000). Furthermore, a preferential increase in a specific subunit is elicited by the differential transcriptional regulation of the $\mathrm{H}$ - and Lsubunit genes. The differentiation of various cells is associated with a consistent increase of ferritin mRNA and ferritin levels, and a preferential accumulation of the $\mathrm{H}$-subunit as a consequence of a selective transcriptional regulation of the $\mathrm{H}$-subunit gene needed to produce ferritin with a structure appropriate to a differentiated cell type (Festa et al., 2000; Harrison \& Arosio, 1996; Theil, 1990). During inflammation, stimulation by the cytokine tumour necrosis factor (TNF), results in transcriptional up-regulation of the $\mathrm{H}$-subunit without a change in L-subunit expression. This gives rise to an increase in the $\mathrm{H}$-subunit to L-subunit ratio of the produced ferritins (Festa et al., 2000). Up-regulation of the transcription of the $\mathrm{H}$-subunit gene has also been found in cell lines overexpressing c-myc, in the pregnant uterus, in denervated skeletal muscle, in the atherosclerotic aorta, in response to other cytokines and after exposure to exogenous heme (Ponka et al., 1998). Somewhat surprising, iron itself does not seem to affect the amount of $\mathrm{H}$-subunit mRNA, although it has a stimulatory effect on the accumulation of L-subunit mRNA (Ponka et al., 1998). L-subunit gene transcription and total cellular Lsubunit mRNA appear to be dramatically increased by iron, whereas $\mathrm{H}$-subunit transcription rates and H-subunit mRNA levels are only slightly increased (White \& Munro, 1988).

\section{The gene sequences of the H-subunit and the L-subunit of ferritin}

The genes for the $\mathrm{H}$ - and L-subunits are contained on different chromosomes-the gene for the $\mathrm{H}$ subunit on chromosome 11 and the gene for the L-subunit on chromosome 19 (Worwood, 1990). The genes for the $\mathrm{H}$ - and L-subunit contain three introns and four exons (Torti \& Torti, 2002) and the gene sequences for these two subunits show extensive homology in their coding regions with several common stretches of $20-30$ nucleotides. However, they differ markedly in their non-coding regions 
(Boyd et al., 1985). These differences are extremely important for differential regulation of the expression of the genes for these two subunits. Functional analysis for the 5 non-coding region for the $\mathrm{H}$-subunit gene but not for the L-subunit gene has been reported. The 5 ' non-coding region of the $\mathrm{H}$ subunit gene contains three regulatory regions. The first of these regions, the B-box, -42 to -62 nucleotides upstream from the start codon and closest to the transcription initiation site is responsive to CAMP. This B-box regulatory region is sensitive to the initiation of transcription by hormones and second messengers and binds a protein complex termed B-box binding factor (Bbf). The B-box binding factor comprises the transcription factor NFY, the co-activator p300, and the histone acetylase p300/CBP associated factor (PCAF) (Harrison \& Arosio, 1996; Torti \& Torti, 2002). The second regulatory region identified in the 5 non-coding region of the $\mathrm{H}$-subunit gene includes a region called the A-box at position - 109 to - 132 upstream from the start codon (transcription initiation site), which contains a consensus sequence for binding the polymerase II transcription factor SP1 responsible for about $50 \%$ of the activation of gene expression in several cell lines (Harrison \& Arosio, 1996; Torti \& Torti, 2002). The third regulatory region consists of a stretch of $10 \mathrm{Gs}$ which are termed 'G-fer' between -272 and -291 upstream from the start codon. It is suggested that binding of inhibitory factor 1 to this sequence results in the inhibition of $\mathrm{H}$-subunit gene transcription (Harrison \& Arosio, 1996; Torti \& Torti, 2002).

\section{Translational regulation of the H-subunit and L-subunit mRNA expression via metabolically available iron}

Ferritin is the major intracellular protein involved in storage and detoxification of iron. It is therefore not surprising that the expression of ferritin is extremely sensitive to the amount of metabolically available iron. In order to accomplish a finely tuned system of ferritin expression as a function of the size of the metabolically available iron pool (the labile iron pool) it is important that the ferritin gene structure contains sequences that sense the size of the labile iron pool (Harford et al., 1994). The 5'-untranslated region (5-UTR) of both the $\mathrm{H}$ - and L-subunit mRNA contains a highly conserved 28-base sequence known as the iron-responsive element (IRE) sensitive to the metabolically available active iron (Worwood 1990). The IREs are comprised of cis-acting nucleotide sequences. These nucleotide sequences form stem-loop structures that contain a six-membered loop with the sequence CAGUGN (Ponka et al., 1998). These stem-loop structures are recognized by trans-acting cytosolic RNA-binding proteins required for the co-ordinated expression of the $\mathrm{H}$ - and L-subunits (Theil, 1990). These cytosolic RNA-binding proteins, IRP1 and IRP2, cause a decrease in $\mathrm{H}$ - and L-subunit mRNA translation by binding to the stem-loop structures of the $5^{\prime}$-UTR of the respective mRNAs. IRP1 and IRP2 mediate the translational efficiency by obscuring the subsequent binding of the 435 translation pre-initiation complex needed for the initiation of translation (Rogers et al., 1994). IRP1 and IRP2 both sense and homeostati-cally control the metabolically available iron. For IRP1 this is accomplished by the existence of two conformationally distinct forms. IRP1 is a $90 \mathrm{kDa}$ iron - sulphur cluster protein. When iron is abundant it exists as a cytosolic aconitase. When iron is scarce it assumes an open configuration associated with the loss of iron atoms from the iron - sulphur cluster and the subsequent binding to the IRE stem-loop structure, acting as a repressor of ferritin translation (Torti \& Torti, 2002). In contrast, the $105 \mathrm{kDa}$ IRP2 protein is regulated by degradation: IRP2 protein is abundant in iron scarcity, but is degraded rapidly in iron excess through targeting of a unique 73 amino acid sequence and subsequent oxidation and ubiqui-tination (Meyron-Holtz et al., 1999; Torti \& Torti, 2002). This 
response of ferritin synthesis to the size of the metabolically available pool of iron endows the cell with an exceptionally rapid system for increasing ferritin synthesis upon iron influx. Iron influx increases the labile iron pool and, via binding to the IRP1 and IRP2, causes a rapid increase in ferritin translation. This rapid response is achieved by a shift of stored mRNA from the ribonucleoprotein (RNP) fraction to polysomes (translational shift) (White \& Munro, 1988). The translation of existing ferritin mRNA is more rapid than additional ferritin gene transcription followed by translation. The ferritin response to iron influx can thus be viewed as a protective rapid response system, allowing immediate formation of additional ferritin in which to store the surplus iron (Truty et al., 2001). Both the H-subunit and L-subunit mRNA shift from the RNP fraction to polysomes to the same extent (White \& Munro, 1988). Nevertheless, the transcription of the L-subunit gene is preferentially stimulated by an increase in metabolically available iron (Worwood, 1990) and results in an increase in the ratio of L-subunit to $\mathrm{H}$ subunit mRNA, which appears first in the RNP fraction and later in the polysomes (White \& Munro, 1988). This increase in the L-subunit to $H$-subunit mRNA ratio in the poly-somes accounts for the change in the ratio of L-subunit to $\mathrm{H}$-subunit protein synthesis following iron administration (White \& Munro, 1988). Therefore, co-ordinated translational control and differential transcriptional control exists between these two genes (White \& Munro, 1988).

\section{Translational regulation of $\mathrm{H}$-subunit and L-subunit expression irrespective of metabolically available iron}

Various factors other than iron may alter the translational efficiency of the $\mathrm{H}$ - and L-subunit mRNA. This may be accomplished by binding of regulatory factors to specific sequences in the 5-UTR other than the IRE or by changing the efficiency of the interaction between the IREs and IRPs. One specific sequence responsible for translational control is the 20 -nucleotide sequence downstream from the IRE known as the acute box (Thomson et al., 1999). This sequence responsible for the enhancement of translation operates after iron-dependent translational initiation and the formation of the 43S ferritin mRNA scanning complex (Rogers et al., 1994). Factors that can influence the efficiency of the interaction between the IRE and IRP include cytokines (Piñero et al., 2000), various hormones, that changes the phosphorylation status of the iron-responsive proteins (Thomson et al., 1999; Torti \& Torti, 2002), oxidative stress-reactive oxygen species (Coccia et al., 1992), hemin (Coccia et al., 1992), phosphatases, hypoxia and reoxygena-tion (Thomson et al., 1999) and nitric oxide (NO) that causes the activation of both IRP1 and IRP2. Mechanisms hypothesized to underlie NO-mediated induction of IRP binding activity include cluster disassembly (IRP1), intracellular iron chelation (IRP1 and IRP2), or increased de novo synthesis (IRP2) (Torti \& Torti, 2002).

\section{The degradation of ferritin}

Two different processes can result in the degradation of cytosolic ferritin. The first of these involves the $20 S$ proteasome enzymatic system in the cytosol, and the second, degradation in the lysosome by proteolytic enzymes. Depending on the type of cell, the iron status and whether ferritin is degraded free in the cytosol or within a lysosome, different amounts of iron are made available for metabolic processes. Degradation of ferritin in the cytosol results in the complete release of the iron from ferritin, whereas degradation of ferritin in the confinements of a lysosome can result in the entrapment of ferritin iron (Wixom et al., 1980). Iron-containing ferritin can ultrastructurally be identified in the cytosol as either randomly dispersed ferritin particles or as clusters of ferritin particles. The ferritin clusters in 
the cytosol are accumulations of ferritin in which ferritin particles can be individually resolved. The existence of ferritin either as randomly dispersed ferritin particles or as clusters of ferritin particles depends on the magnitude of iron handling of the different cell types. In cell types handling relatively low quantities of iron, iron-containing ferritin occur as rare, isolated particles whereas in cell types handling greater quantities of iron such as haemopoietic bone marrow cells and cells of the reticuloendothelial system, iron-containing ferritin occurs more frequently as clusters (lancu, 1992). In most clusters the particles are of the iron-rich variety and thus appear larger and more electron dense than the dispersed cytosolic ferritin (lancu 1992). Cluster formation prevents access of the proteins involved in the cytosolic degradation of ferritin and in this way protects the ferritin molecule against degradation. This may be a regulatory step in the pathway of ferritin degradation and iron release. However, as long as the ferritin cluster is not enclosed by a membrane, degradation of these ferritin clusters can result in the release of iron in times of iron shortage. Various studies indicated that the formation of large iron-rich ferritin particles, as a result of an increase in intracellular iron, results in the protection of ferritin molecules against degradation (lancu, 1982; Truty et al., 2001; Worwood, 1982) and that iron-depleted ferritin is easily degraded (Halliday \& Powell, 1979; Wixom et al., 1980). The $20 \mathrm{~S}$ proteasome enzymatic system is responsible for the degradation of damaged intracellular proteins and can recognize specifically, and degrade, oxidized proteins (Mehlhase et al., 2005; Rudeck et al., 2000). The ferritin protein shell is confronted by a multitude of possible oxidative stressors. The oxidation of $\mathrm{Fe}^{2+}$ by the ferroxidase centre of the $\mathrm{H}$-subunit results in the production of $\mathrm{H}_{2} \mathrm{O}_{2}$ which could oxidize the protein shell, and the surrounding $\mathrm{Fe}^{2+}$ can promote oxygen radical production by Fenton type chemistry. Oxidation of ferritin results in the loss of ferritin function and targeting of ferritin to the proteasome degradation system of the cell (Mehlhase et al., 2005; Rudeck et al., 2000). Oxidation of ferritin can also result in aggregation of ferritin molecules. Sulfhydryl groups, particularly, are oxidized followed by aggregation of ferritin as a result of the formation of disulfide bridges between ferritin molecules (Welch et al., 2001). The H-subunit contains a cysteine at position 90 located on the BC-loop facing the exterior which is extremely susceptible to oxidation (Welch et al., 2002).

Ferritin cluster formation, however, might also stimulate the uptake of ferritin into lysosomes whereupon less iron will be released during ferritin degradation. The reason for this is that the release of iron during the degradation process relies on the accessibility of the iron core to the reducing system of the cell since dissolution of the iron core is generally determined by the reduction of $\mathrm{Fe}^{3+}$ to $\mathrm{Fe}^{2+}$. Therefore degradation of the ferritin protein shell in the cytosol gives $\mathrm{FMNH}_{2}$ (the reducing system of the cell) easy access to the $\mathrm{Fe}^{3+}$-ions and results in the complete dissolution of the iron core. The generated $\mathrm{Fe}^{2+}$-ions are re-utilized in metabolic processes or incorporated into new ferritin molecules. If, however, ferritin is degraded within a secondary lysosome (charged with proteolytic enzymes) the iron can no longer readily be made available because it has been cut off from the $\mathrm{FMNH}_{2}$ reducing system (Wixom et al., 1980). Instead digestion by lysosomal enzymes would proceed, and the resulting aggregates of iron oxyhydroxide (ferritin cores) would no longer be provided with a mechanism for mobilizing and recycling their iron. This will result in aggregation of the ferritin cores and the formation of haemosi-derin (Wixom et al., 1980). Cytosolic degradation may therefore be the major iron turnover mechanism providing the cell with easily accessible iron for shunting into metabolic pathways, while degradation within membrane-encapsulated secondary lysosomes, with subsequent haemosiderin formation, may prevent the uncontrolled release of iron and may become prominent when there is iron overload (Harrison \& Arosio, 1996; Wixom et al., 1980). Nevertheless, degradation of ferritin in 
lysosomes can also produce soluble iron, although these larger masses of ferritin/haemosiderin may require more time for the release of their iron contents. The iron so released would then be translocated back to the cytosol for reutilization in metabolic processes or sequestration by ferritin (Deiss, 1983; Ponka et al., 1998; Radisky \& Kaplan, 1998). Thus it seems that the release of iron from lysosomes depends on the magnitude of aggregate formation and the subsequent deposition of iron as haemosiderin.

\section{The formation of haemosiderin from ferritin}

The absolute and relative amounts of iron stored in the form of the two iron reserves, ferritin and haemosiderin, vary with iron loading and cell type (Ford et al., 1984). There is slightly more ferritin than haemosiderin in the liver and spleen when total tissue iron content is normal. As total iron content increases a progressively higher percentage of iron occurs as haemosiderin (Ford et al., 1984; Miyazaki et al., 2002; Ringeling et al., 1989; Wixom et al., 1980; Worwood 1990). With overloading syndromes such as primary and secondary haemochromatosis, the iron content of haemosiderin can increase up to a 100-fold, whereas that of ferritin only increases 5- to 10-fold (Powell, 1998).

There is enough evidence to believe that haemosiderin is derived from ferritin as a result of degradation of the ferritin protein shell in secondary lysosomes (Finch et al., 1984; Fischbach et al., 1971; Ford et al., 1984). For instance, haemosiderin contains various amounts of degraded ferritin, as well as aggregated dense particles of irregular shape with diameters ranging from 10 to $75 \AA$, which ultrastructurally resemble iron cores (Ringeling et al., 1989; Wixom et al., 1980), and haemosiderin granules are recognised by anti-ferritin antibodies (Harrison \& Arosio, 1996). Ferritin is frequently situated in secondary lysosomes and autophagosomes of normal cells, such as hepatocytes and macrophages but its quantity in these organelles increases greatly after loading with iron (Richter, 1978)—demonstrating the protective function of haemosiderin formation against the toxicity of iron. Ferritin finds its way into lysosomes by autophagocytosis and/or fusion of ferritin clusters with the lysosomal membrane. Autophagocytosis is responsible for the turnover of cellular constituents including cellular proteins and involves the formation of autophagic vacuoles by invagination of intracytoplasmic membranes enclosing a relatively large volume of cytoplasm, together with various cellular constituents (Wixom et al., 1980). The autophagic vacuole receives digestive enzymes by fusion with a primary or secondary lysosome and becomes an autophagosome (Wixom et al., 1980). It is within this lysosomal organelle that the ferritin protein shell is degraded by the action of lysosomal proteases (Richter, 1984). It is suggested that the polymerization of ferritin (formation of oligomers of ferritin), which results in a change in solubility, heat stability and surface charge, may predispose ferritin to incorporation within lysosomes and transformation into haemosiderin (Chiancone \& Stefanini, 1984; Ringeling et al., 1989). Only once the ferritin protein shell has been modified, most probably by denaturation, resulting in the formation of insoluble ferritin molecules, does proteolytic decomposition of the ferritin protein shell by lysosomal enzymes take place (Richter, 1984). However, not all ferritin molecules in these lysosomal organelles are susceptible to the action of lysosomal proteases. Degradation of the ferritin protein shell results in the exposure of the iron oxyhydroxide mineral cores followed by aggregation of these oxyhydroxide particles and the formation of insoluble masses of iron oxyhydroxide (haemosiderin) (Fischbach et al., 1971; Richter, 1978; Weir et al., 1985). Although the main purpose of the formation of haemosiderin would appear to be protection against iron overload, these larger masses of ferritin/ haemosiderin can, at a much slower rate, also release iron. This iron is 
then translocated back to the cytosol for re-utilization in metabolic processes or sequestration by ferritin (Deiss, 1983; Ponka et al., 1998; Radisky \& Kaplan, 1998). Haemosiderin is not, however, necessarily the end product as massive quantities of iron oxyhydroxide (haemosiderin) from these secondary lysosomes, can accumulate to form cytoplasmic organelles known as siderosomes (Richter, 1978). The haemosiderin-containing siderosomes can thus be regarded as the end-product of secondary lysosome action in which the wall of the original secondary lysosome now encapsulates the digested ferritin iron cores (Harrison \& Arosio, 1996; Wixom et al., 1980)-although clusters of electrondense material without membranes or only partially enclosed membranes can also occur (Deiss, 1983; Harrison \& Arosio, 1996; lancu, 1982). Within siderosomes, ferritin can be identified as individual particles, in clusters, in paracrystalline hexagonal arrays, or forming circular arrangements (lancu, 1992). Siderosomes not only contain ferritin and haemosiderin, but occasionally also contain electrondense amorphous or spicular iron-containing compounds which have as yet not been identified biochemically or ultrastructurally. In cells with marked iron overload, solitary siderosomes seem to fuse and form larger bodies described as 'compound siderosomes' (lancu, 1992).

\section{The increased susceptibility of $\mathrm{H}$-subunit rich ferritins to degradation}

It is suggested that $\mathrm{H}$-subunit rich ferritins are turning over more rapidly than L-subunit rich ferritins (Boyd et al., 1985; Truty et al., 2001; Worwood, 1982). Haemosiderin, which contains the degraded ferritin molecules as a result of the lysosomal breakdown of ferritin, shows the predominance of denatured subunits to be of the H-subunit type (Miyazaki et al., 2002). It was shown that ferritin is more abundant in the iron overloaded liver than in the normal liver, and that it is richer in L-subunits displaying a L-subunit : H-subunit ratio from $5: 1$ to $12: 1$. In contrast, haemosiderin displayed a predominance of denatured H-subunits over denatured L-subunits (Miyazaki et al., 2002). A mechanism may therefore exist for preferentially directing ferritins rich in the H-subunit into lysosomes resulting in the formation of haemosiderin containing a high proportion of denatured $\mathrm{H}$-subunits. It was shown, in vitro, that a too great proportion of $\mathrm{H}$-subunits in the ferritin protein shell result in ferritin aggregation. This may be due to the inadequacy of the ferritin protein shell to retain the formed $\mathrm{Fe}^{3+}$ resulting in the loss of $\mathrm{Fe}^{3+}$ and hydrolysis of $\mathrm{Fe}^{3+}$ on the outside of the ferritin molecule (Harrison \& Arosio, 1996). This may be the signal for ferritin to be incorporated into lysosomes. Once inside the lysosome the presence of a large number of $\mathrm{H}$-subunits in the ferritin protein shell increases the chances of degradation (Bomford et al., 1981), since H-subunit rich ferritins, in the presence of denaturing conditions, are less stable than L-subunit rich ferritins (Kim et al., 2001; Miyazaki et al., 2002). The salt-bridge present in the L-subunit appears to be important for the differences in stabilities between $\mathrm{H}$-subunit rich ferritins and L-subunit rich ferritins (Arosio et al., 1991). Futhermore, H-subunit rich ferritins are more susceptible to proteolysis due to less ordered secondary structures (Bomford et al., 1981). In particular the loop $L$ becomes more exposed and/or less immobilized when the proportion of $\mathrm{H}$-subunits increases and therefore more accessible to lysosomal enzymes (Chiancone \& Stefanini, 1984).

\section{The reticulo-endothelial cell and haemosiderin formation}

The reticulo-endothelial cell responsible for taking up and digesting effete red blood cells are confronted by tremendous amounts of iron as a result of the breakdown of the heme contained by the red blood cells. These surplus amounts of iron could result in iron-induced damage to the reticulo- 
endothelial cell. In order to prevent possible iron-induced damage, the reticulo-endothelial cell is capable of storing vast amounts of iron as haemosiderin. The reticulo-endothelial cell takes up red blood cells and incorporates these red cells into phagocytic vacuoles, where digestion of the red blood cell and degradation of heme take place. The heme contained by the red blood cell is degraded in 5 hours. However, remnants of the red blood cells could still be detected in the phagocytic vacuoles 24 hours after uptake of red blood cells by the reticulo-endothelial cell. At this time, moderate numbers of free ferritin molecules are present in the cytosol. Forty-eight hours after red blood cell uptake the number of ferritin molecules in the cytosol is increased and continue to accumulate in the cytoplasm up to 96 hours after red blood cell uptake. However, from 48 hours onward ferritin is translocated into aggregates situated in autophagic vacuoles by a process of invagination of intracytoplasmic membranes followed by the formation of haemosiderin (Wixom et al., 1980). The formation of haemosiderin in reticuolendothelial cells and other macrophage-like cells are influenced by inflammatory and infectious conditions. Macrophages subjected to increased oxidative stress also degrade ferritin faster (Mehlhase et al., 2005). It is therefore suggested that during inflammatory and infectious conditions the proportion of poorly accessible (non-chelatable) iron associated with ferritin similarly increases, suggesting a pathway from non-ferritin iron, to loosely associated ferritin iron, to a well-sequestered non-chelatable form existing as haemo-siderin (Fahmy \& Young, 1993). Cytokines such as tumour necrosis factor- $\alpha$ (TNF- $\alpha$ ) and interferon- $\gamma$ (IFN- $\gamma$ ) may be responsible for this effect during inflammatory and infectious conditions. These cytokines may increase lysosomal activity resulting in increased degradation of intracellular ferritin, leading to the formation of haemosiderin, from which iron would be less easily liberated for subsequent extra-cellular release (Alvarez-Hernández et al., 1989). In vitro incubation of cells with either TNF- $\alpha$ or IFN- $\gamma$ increases the expression of ferritin $\mathrm{H}$ subunit mRNA but not L-subunit mRNA (Fahmy \& Young, 1993). Such a differential regulation of ferritin subunit expression might result in increased amounts of haemosiderin formation since $\mathrm{H}$-subunit rich ferritins are more susceptible to lysosomal degradation.

\section{Ferritin in cellular organelles}

\section{Nuclear ferritin}

$\mathrm{H}$-subunit rich ferritins are transiently present in the nucleus where the presence of these $\mathrm{H}$-subunit rich ferritins can be controlled by various factors such as abnormal increases in cellular iron levels, developmental status, pro-inflammatory cytokines and oxidative stress (Thompson et al., 2002). A specific pathway has been shown for the translocation of cytoplasmic $\mathrm{H}$-subunit rich ferritins, but not cyto-plasmic L-subunit rich ferritins, into the nucleus (Surguladze et al., 2005). This pathway for the transportation of cytoplasmic $\mathrm{H}$-subunit rich ferritins into the nucleus involves the nucleur pore complex (NPC) (Thompson et al., 2002), and the translocation is an active process that requires energy in the form of ATP (Surguladze et al., 2005; Thompson et al., 2002). Although many proteins are translocated into the nucleus by binding of a nuclear localization signal to the nuclear pore complex, no such nuclear localization signal could be identified for $\mathrm{H}$-subunit rich ferritins. However, since $\mathrm{H}$-subunit rich ferritins, as well as the $\mathrm{H}$-subunit rich ferritin mutant containing no ferroxidase centre, are translocated to the nucleus, but L-subunit rich ferritins are not, specific amino acids on the outside of the $\mathrm{H}$-subunit rich ferritin molecule are implicated in this process (Thompson et al., 2002). O-glycosylation is predicted as the cue for the specific translocation of $\mathrm{H}$-subunit rich ferritins. Once the $\mathrm{H}$-subunit rich ferritins are inside the nucleus these ferritins can form stable complexes with the DNA (Surguladze et al., 2004). 
This places the $\mathrm{H}$-subunit rich ferritins in a strategic position to ward off possible oxidative onslaughts to DNA or, alternatively, to donate iron for enzyme activity and possibly the nicking of double stranded DNA that could result in relaxation of superhelical stress (Surguladze et al., 2004). It was shown that not only does $\mathrm{H}$-subunit rich ferritin form a stable complex with DNA (Surguladze et al., 2004), but that DNA also contains specific iron-binding sites (Thompson et al., 2002).

Although the precise functions of $\mathrm{H}$-subunit rich ferritins in the nucleus are still somewhat unclear indications are that $\mathrm{H}$-subunit rich ferritin protects DNA and other nuclear constituents against oxidative damage (Thompson et al., 2002), that it donates iron for iron-dependent enzyme or transcription activities (Surguladze et al., 2004) and that it may play a role in the regulation of the transcription of specific genes (Broyles et al., 2001).

\section{Mitochondrial ferritin}

Mitochondrial ferritin is found in the matrix of the mitochondria under specific physiological conditions, but is low in most cell types. Mitochondrial ferritin is, in general, structurally and functionally analogous to cytosolic ferritin and its main function, similar to that of cytosolic ferritin, is to sequester surplus iron. It does, however, differ from cytosolic ferritin in various aspects (Levi et al., 2001). Where the ferritin present in the cytosol exists mainly as heteropolymers consisting of different combinations of the $\mathrm{H}$ and the L-subunit, mitochondrial ferritin consists of only homopolymers of a subunit similar to the $\mathrm{H}$ subunit of cytosolic ferritins (Levi et al., 2001). The mitochondrial ferritin subunit is encoded from an intronless gene located on chromosome $5 q 23.1$, which is different from the $\mathrm{H}$-subunit gene for the cytosolic ferritin. Nevertheless, a high degree of sequence homology exists between the cytosolic $\mathrm{H}$ subunit and the mitochondrial ferritin subunit (Bou-Abdallah et al., 2005; Levi et al., 2001). The mitochondrial ferritin subunit has about $80 \%$ sequence identity to cytosolic ferritin $\mathrm{H}$-subunit in its coding region and $55 \%$ to that of the cytosolic ferritin L-subunit (Drysdale et al., 2002), with a structure very similar to H-subunit ferritin (Levi \& Arosio, 2004). More important, the mitochondrial ferritin subunit has complete conservation of the amino acids constituting the ferroxidase centre (Levi \& Arosio, 2004). The mitochondrial ferritin gene is expressed in the cytosol as a $30 \mathrm{kDa}$ polypeptide containing an $\mathrm{N}$ terminal mitochondrial targeting sequence of 60 amino acids. Once the $30 \mathrm{kDa}$ polypeptide enters the matrix space of the mitochondria the targeting sequence is removed and the polypeptide processed into a subunit of $22 \mathrm{kDa}$ (Levi et al., 2001). Typical hollow spherical ferritin shells containing 24 subunits are then assembled from these subunits.

As mitochondrial ferritin contains ferroxidase activity it can take up large amounts of iron. However, the ferroxidase activity is significantly lower than that of $\mathrm{H}$-subunit rich cytosolic ferritin (Bou-Abdallah et al., 2005). This is partially due to the fact that only 12 of the 24 ferroxidase centres of mitochondrial ferritin would appear to be actively oxidizing $\mathrm{Fe}^{2+}$ to $\mathrm{Fe}^{3+}$, and this at a reduced rate, and although an $\mu-$ peroxodiferric intermediate is formed, mitochondrial ferritin does not regenerate its ferroxidase centre. The underlying reason that only some of the ferroxidase centres are involved in the oxidation process is that the side-chain of serine, in place of alanine at position 144, protrudes toward a channel that connects to the ferroxidase centre-a configuration that may create steric hindrance to the movement of iron accounting for only 12 active ferroxidase centres and a stoichiometry of $24 \mathrm{Fe}^{2+}$ oxidized per ferritin molecule. The oxidized $\mathrm{Fe}^{3+}$ is stabilized followed by nucleation. The negative patch of glutamic 
acid residues near the ferroxidase centre, similar to that for the L-subunit of cytosolic ferritin, might constitute the nucleation site. Once nucleation has taken place autocatalytic mineral surface oxidation of iron occurs, resulting in slower oxidation of iron, but less $\mathrm{H}_{2} \mathrm{O}_{2}$ production early in the process of core formation (Bou-Abdallah et al., 2005).

The iron in the cytosol transverses the double membrane of the mitochondria and is therefore readily taken up by mitochondrial ferritin (Corsi et al., 2002). Mitochondrial ferritin, in vitro, takes up iron in a similar fashion as cytosolic ferritin, where $\mathrm{Fe}^{2+}$ is initially oxidized to $\mathrm{Fe}^{3+}$ by a ferroxidase centre. This is then soon followed by iron-nuclei formation and autocatalytic $\mathrm{Fe}^{2+}$ oxidation on the mineral surfacesince mitochondrial ferritin do not regenerate its ferroxidase centres. This process was shown to occur at a slower rate than for cytosolic $\mathrm{H}$-subunit rich ferritin. Despite the slower uptake, in vivo mitochondrial ferritin displays a higher avidity for iron than cytosolic $\mathrm{H}$-subunit rich ferritin. Although excess iron, even when processed by mitochondria, is said not to be retained in mitochondrial ferritin, but is sequestered into cytosolic ferritin (Corsi et al., 2002), it would appear that over-expression of mitochondrial ferritin can lead to the depletion of cytosolic iron. In situations where increased amounts of mitochondrial ferritin are available cytosolic ferritin and mitochondrial ferritin competes for cytosolic iron and since mitochondrial ferritin has a higher avidity for iron this can lead to the accumulation of iron in mitochondrial ferritin (Corsi et al., 2002). This depletion of cytosolic iron dramatically increases IRP binding to IREs, followed by a decrease in cytosol ferritin levels and an increase in transferrin receptor expression (Corsi et al., 2002; Nie et al., 2005). In short, it would at present appear that the high avidity of mitochondrial ferritin for iron, together with a low availability of this iron for chelation, could lower iron bio-availability in the cytosol (Nie et al., 2005). The functional implication of this is as yet not clear.

Under normal conditions most cell types contain only low amounts of mitochondrial ferritin and the stimuli for the expression of mitochondrial ferritin is still somewhat unclear. As mitochondrial ferritin does not contain an iron responsive element in its 5 untranslated region, as is the case for the $\mathrm{H}$ subunit and L-subunit of cytosol ferritin (Levi et al., 2001), one would presume that the expression of mitochondrial ferritin is not regulated by the labile iron pool as for cytosolic ferritin. However, when heme synthesis fails in patients with sideroblastic anaemia an increase in mitochondrial ferritin occurs together with the occurrence of ring sideroblasts (Cazzola et al., 2003).

Although details of the regulation of mitochondrial ferritin expression are not known the purpose of the presence of ferritin in the mitochondria is self-evident. The mitochondrium is confronted with a great amount of iron since most of the metabolically active iron of the cells is processed in the mitochondria due to the synthesis of heme and iron-sulphur complexes (Bou-Abdallah et al., 2005; Nie et al., 2005). Not only are mitochondria surrounded by iron but mitochondria also produce great amounts of reactive oxygen species during oxidative respiration. This combination of iron and reactive oxygen species in the mitochondrium calls for the protection provided by mitochondrial ferritin in times of iron dyshomeostasis that may result in the oxidative damage of mitochondrial constituents (Nie et al., 2005).

\section{Extracellular ferritin}

Most of the synthesized ferritin remains within the cell where it sequesters and releases iron in order to maintain intracellular iron homeostasis. However, the content of ferritin varies between different cell 
types and maturation stages. The content of ferritin in peripheral white blood cells, for instance, is about $10^{3}$ times higher than that of peripheral red blood cells, with monocytes showing the highest values (Invernizzi et al., 1990). Aside from the presence of ferritin in the cytosol of the cell, various quantities of ferritin are found in the plasma. It is suggested that ferritin may enter the circulation either via secretion of ferritin by cells or through the release of ferritin from damaged cells (Worwood, 1990). Both mechanisms probably contribute to plasma levels. Ferritin destined for intracellular iron homeostasis is synthesized on free polyribosomes whereas a small amount of ferritin may be synthesized on the rough endoplasmic reticulum for secretion into the plasma (Covell \& Worwood, 1984; Cragg et al., 1981). The range of plasma ferritin in the normal adult varies from 15 to $300 \mu \mathrm{g} / \mathrm{l}$ (Covell \& Worwood, 1984; Worwood, 1990), and consists mainly of glycosylated L-subunit rich ferritins containing insignificant amounts of iron, even in conditions of iron overload (Covell \& Worwood, 1984; Cragg et al., 1981; Jacobs \& Worwood, 1975; Ponka et al., 1998). While the iron content of ferritin in the liver and spleen could be more than $0.2 \mu \mathrm{g} F / \mu \mathrm{g}$ protein in conditions of iron overload, the iron content of plasma ferritin can be as low as $0.02-0.07 \mu \mathrm{g}$ Fe/ $\mu \mathrm{g}$ protein (Worwood et al., 1976).

The regulation and functions of secreted ferritins in the plasma remain an enigma. However, a quantitative relationship exists between the level of plasma ferritin and the amount of storage iron (Cazzola \& Ascari, 1986). In conditions of iron overload there is generally an increase in the expression of intracellular L-subunit rich ferritins, paralleled by an increase in these ferritins in the plasma (Halliday \& Powell, 1979). Although the specific cellular origin of plasma ferritin is not known (Torti \& Torti, 1994), various experiments indicated a large contribution made by the reticuloendothelial cell. An increase in plasma ferritin levels is known to occur in parallel with the increase in reticulo-endothelial cell ferritin after an increase in reticulo-endothelial cell iron during phagocytosis of non-viable red blood cells (Finch et al., 1984; Jacobs \& Worwood, 1975). However, elevated plasma ferritin levels are also seen in patients with parenchymal iron overload whose reticulo-endothelial cells are virtually devoid of iron (Finch et al., 1984). Therefore it would appear that the plasma ferritin reflects storage iron anywhere in the body, regardless of the type of cell in which it was stored (Finch et al., 1984). However, plasma ferritin concentration is affected by a number of factors other than the amount of storage iron, including tissue necrosis, damage to ferritin-rich tissue, inflammation, infections, neoplastic disease, and increased red blood cell turnover (Cazzola \& Ascari, 1986; Hershko \& Konijn, 1984; Torti \& Torti, 1994; Worwood, 1982). When any of these conditions are present the relationship between plasma ferritin concentration and amount of storage iron no longer holds. With tissue necrosis as in hepatocellular injury the increase in plasma ferritin is for instance due to the release of ferritin from the damaged cells since the increase in ferritin is dependent on both the magnitude of cellular damage and liver iron stores (Halliday \& Powell, 1979). Furthermore, an increase in non-glycosylated, iron-rich ferritin has been reported upon tissue damage, which is indicative of the release of tissue ferritin from the damaged tissue and not as a result of active secretion (Cragg et al., 1981).

In various neoplastic diseases it is suggested that the increase in plasma ferritin are related to an increased production of ferritin by the malignant cells. In leukaemia the normal concentration of ferritin in circulating leukocytes is increased up to six-fold in acute myeloblastic leukaemia, more than 20-fold in acute myelomonocytic leukaemia and two-to three-fold in chronic granulocytic leukaemia (Jacobs \& Worwood, 1975). In the presence of various solid tumours, including tumours of the breast, pancreas and liver an increase of $\mathrm{H}$-subunit rich ferritins was shown in the cells of the tumour, as well as an 
increase in plasma ferritin. In addition, the plasma ferritins reflected the increase in $\mathrm{H}$-subunit rich ferritins of the tumour, therefore the tumours seem to produce and secrete these $\mathrm{H}$-subunit rich ferritins (Kew et al., 1978; Niitsu et al., 1984).

The concentration of ferritin in plasma is a function of the rate of secretion or release on the one hand, and the clearance by other tissues on the other (Hershko \& Konijn, 1984). The major cell type responsible for the clearance of plasma ferritins is the hepatocyte. A specific receptor for both glycosylated and non-glycosylated ferritin has been demonstrated on the hepatocyte membrane (Hershko \& Konijn, 1984). These receptors bind both the $\mathrm{H}$-subunit and the L-subunit of ferritin (Halliday et al., 1979). However, a significant difference is indicated between the rates of clearance for the non-glycosylated ferritin of tissues and the glycosylated plasma ferritin (Hershko \& Konijn, 1984). These differences in clearance may result in a significantly longer half-life for the glycosylated, secreted ferritins in the circulation compared to that of the non-glycosylated tissue ferritins (Bellotti et al., 1987; Halliday et al., 1979; Hershko \& Konijn, 1984; Worwood, 1990).

\section{The internalization of ferritin by cells}

Iron delivery to cells in general, and to developing erythroid cells in particular, is largely attributed to diferric transferrin (Meyron-Holtz et al., 1994). However, developing erythroid cells possess on their surface, in addition to transferrin receptors, receptors that bind specifically, and internalize, $\mathrm{H}$-subunit rich ferritin (Meyron-Holtz et al., 1994). This binding and internalization of $\mathrm{H}$-subunit rich ferritins is accomplished by means of a specific saturable process and is highly regulated by the iron status of the cell (Meyron-Holtz et al., 1999). Since extra-cellular ferritin, once internalized by the cell, is indistinguishable from intracellular ferritin, extracellular ferritin could possibly also function as an iron donor (Meyron-Holtz et al., 1999). It is, for instance, known that internalized ferritin can increase the cellular labile iron pool and decrease the levels of the iron responsive protein, whereas apoferritin (containing no iron) has the opposite effect. This supports the notion that internalized ferritin is an iron donor and suggests that apoferritin behaves like an iron chelator (Meyron-Holtz et al., 1999).

Developing erythroid cells in the bone marrow are often found in close proximity to a central 'mother' reticuloendothelial cell which 'feeds' ferritin to these developing red cell precursors (Deiss, 1983; Jacobs et al., 1984). This process, known as rhopheocytosis, is a highly regulated pathway for iron assimilation by erythroid progenitor cells while cytosolic ferritin serves as an intermediate pool for iron for haem synthesis (Gelvan et al., 1996; Konijn et al., 1994; Meyron-Holtz et al., 1994). Erythroid progenitor cells contain receptors for ferritin and ferritin finds its way into the erythroid precursors by receptor-mediated endocytosis (Aisen, 1991; Meyron-Holtz et al., 1994). Ferritin binds first to coated invagina-tions or pits before appearing in coated intracellular vesicles, followed by joining of the cytosolic pool of ferritin (Aisen, 1991).

Not only developing eryhroid precursors can take up ferritin, but ferritin is also rapidly internalized by hepatocytes. This presumably also occurs via a receptor-mediated pathway. Other cells, capable of pinocytosis or more generally endocytosis, have also been shown to take up ferritin from extracellular fluid. Therefore, ferritin present intracellulary could have either been synthesized by the cell or could have been taken up (Richter, 1978). Internalized ferritin can subsequently be degraded, similar to 
intracellularly produced ferritin, within the cell (Moss et al., 1994; Siegenberg et al., 1990) and its iron contents released into the labile iron pool of the cell (Hulet et al., 2000).

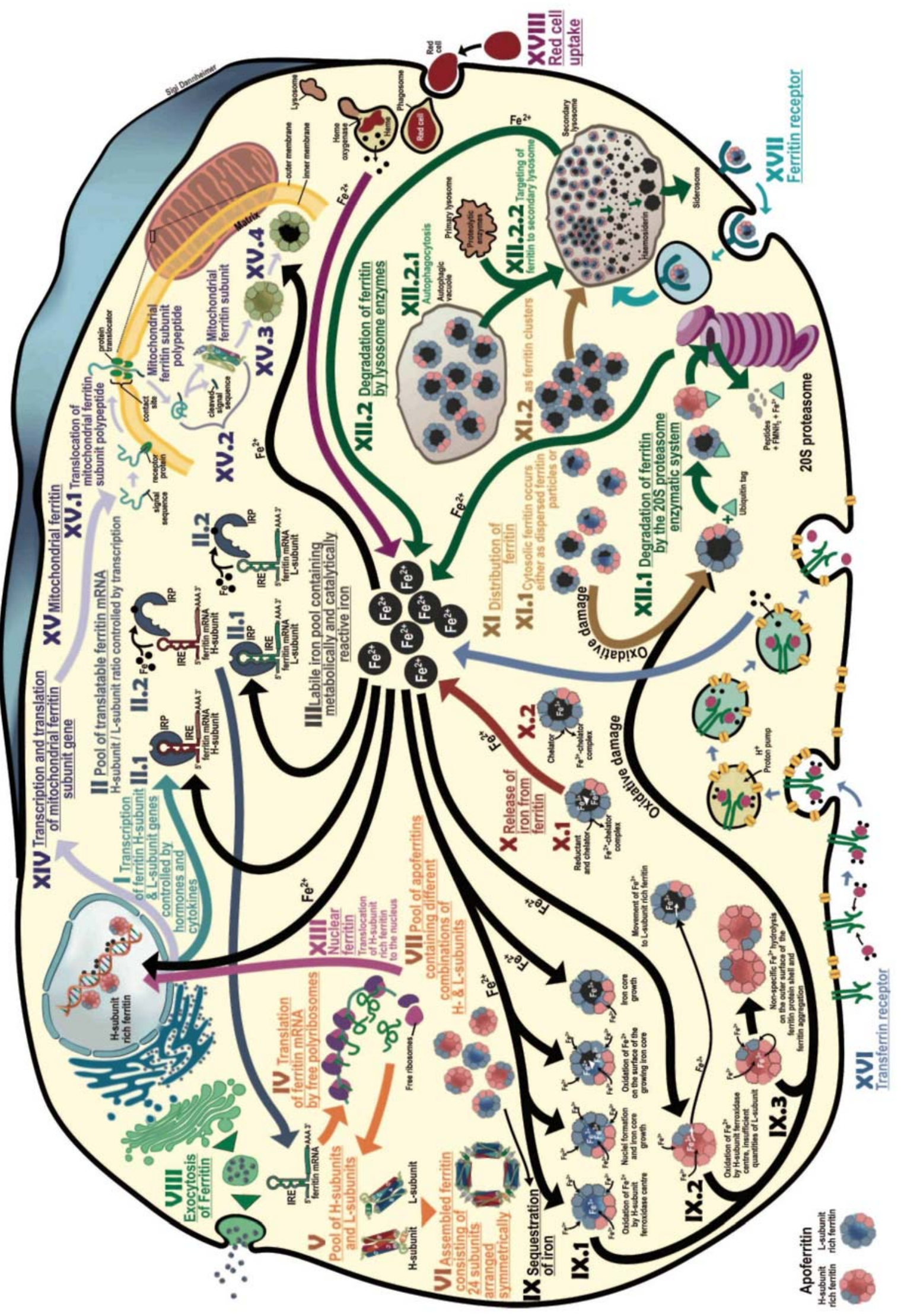

Figure 1. Heuristic presentation of intracellular ferritin metabolism. 


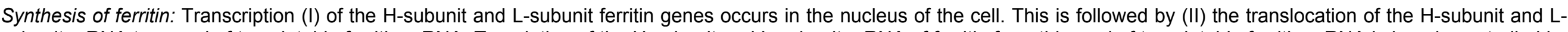

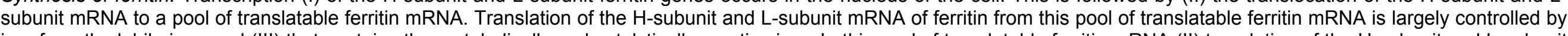

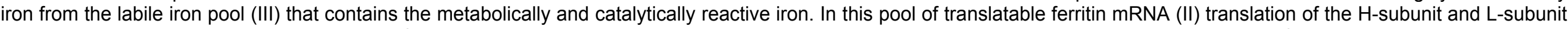

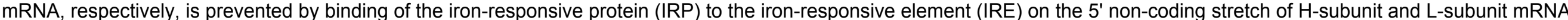

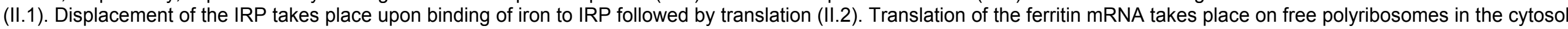

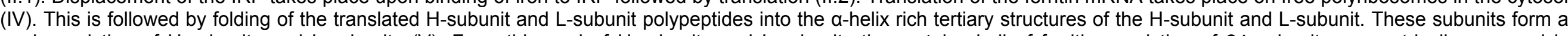

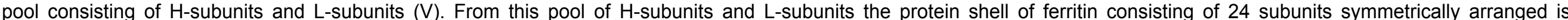

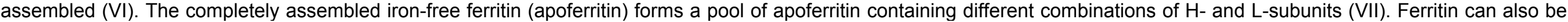
secreted from the cell (VIII).

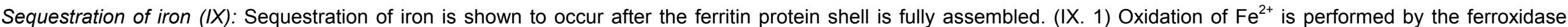

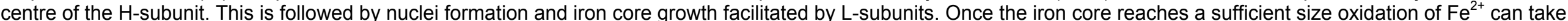

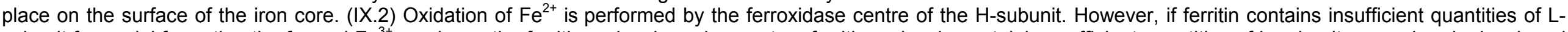

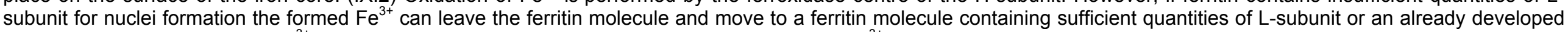
iron core, or (IX.3) the formed $\mathrm{Fe}^{3+}$ can leave the ferritin molecule followed by hydrolysis of the $\mathrm{Fe}^{3+}$ on the outer surface of the ferritin molecule and ferritin aggregation.

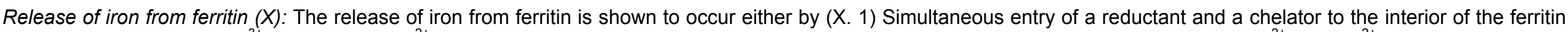

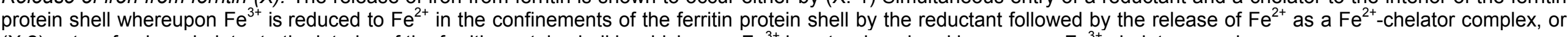
(X.2) entry of only a chelator to the interior of the ferritin protein shell in which case $\mathrm{Fe}^{3+}$ is not reduced and leaves as a Fe ${ }^{3+}$-chelator complex.

Distribution of ferritin (XI): Ferritin occurs in the cytosol either as dispersed ferritin particles (XL 1) or as ferritin clusters (XI.2).

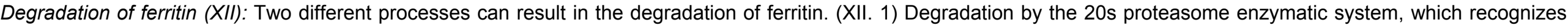

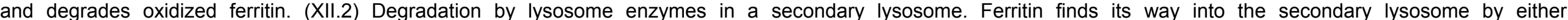
autophagocytosis (XII.2.1) or by targeting of ferritin to the secondary lysosome (XII.2.2). The latter can lead to haemosiderin and eventually siderosome formation.

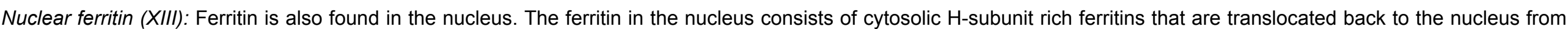
the pool of apoferritin (VII) where these ferritins can form stable complexes with the DNA

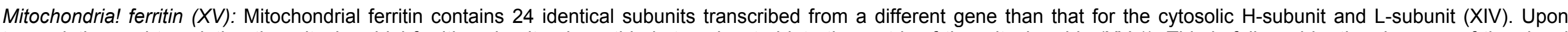

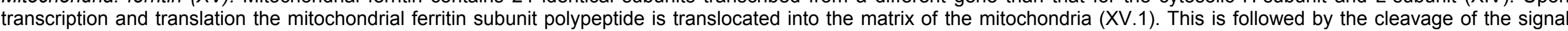

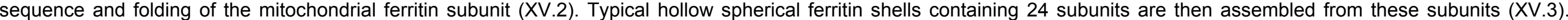
Cytosolic iron from the labile iron pool (III) transverses the double membrane of the mitochondria followed by sequestration by mitochondrial ferritin (XV.4).

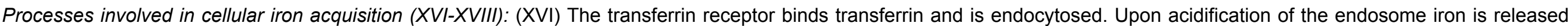

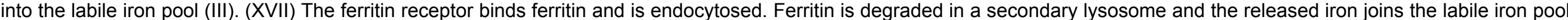

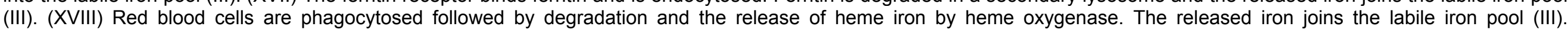




\section{Other functions of ferritin}

Ferritin seems to have functions beyond the control of iron bioavailability-amongst others, the downregulation of myelopoiesis and the suppression of certain immune responses. $\mathrm{H}$-subunit rich ferritins are present in most biologic fluids, but not, or only in low concentrations, in plasma (Morikawa et al., 1995). The ferritin present in plasma is mostly L-subunit rich. However, during certain disease states the concentration of $\mathrm{H}$-subunit rich ferritin is increased. At present it would appear that the $\mathrm{H}$-subunit rich ferritins are derived mostly from monocytes and macrophages as indicated by the secretion of $\mathrm{H}$-subunit rich ferritins from many monocyte-macrophage cell lines, as well as by monocytes from blood and bone marrow (Broxmeyer et al., 1984). The release of $\mathrm{H}$-subunit rich ferritins from monocytes is controlled by T-cell subsets. T-helper cells enhance release and T-suppressor cells suppress the release (Worwood, 1990).

A number of effects have been attributed to these $\mathrm{H}$-subunit rich plasma ferritins including the downregulation of myelopoiesis and the suppression of various immune functions (Broxmeyer et al., 1984; Torti \& Torti, 1994). It has specifically been shown that $\mathrm{H}$-subunit rich ferritins, but not L-subunit rich ferritins, down-regulate myelopoiesis (Broxmeyer et al., 1986), i.e. the growth and development of granulocytes, macrophages, erythrocytes, and platelets (Broxmeyer, 1992; Joshi \& Clauberg, 1988), both in vitro and in vivo. It has been suggested that $\mathrm{H}$-subunit rich ferritins constitute part of a normal inhibitory feed-back mechanism for the proliferation of granulocyte-macrophage colony forming units (CFU-GM), multipotential colony forming units (CFU-GEMM) and erythroid burst forming units (BFU-E) (Broxmeyer, 1992; Jacobs et al., 1984). H-subunit rich ferritin decreases the proliferation of cells during myelopoiesis by directly affecting these progenitor cells (Broxmeyer, 1992). Surface receptors specific for $\mathrm{H}$-subunit rich ferritins have been shown on these progenitor cells (Fargion et al., 1988). These effects of $\mathrm{H}$-subunit rich ferritins are mediated via the ferroxidase activity of the $\mathrm{H}$-subunits-most probably by inducing intracellular iron starvation (Cozzi et al., 2000; Morikawa et al., 1995), since addition of iron completely counteracts the inhibitory effects of the $\mathrm{H}$-subunit rich ferritins (Broxmeyer et al., 1991). Not only does $\mathrm{H}$-subunit rich ferritins down-regulate the production of cells involved in the immune system, but $\mathrm{H}$-subunit rich ferritins also suppress various functions of immune cells. $\mathrm{H}$-subunit rich ferritins can, for instance, exert inhibitory effects on E-rosette formation of T lymphocytes (CD2 is the surface molecule on T-lymphocytes which facilitates binding to sheep erythrocytes and the formation of so-called E-rosettes), suppress the in vitro responses of lymphocytes to various mitogens including PHA and con A, inhibit the mixed-lymphocyte reaction, inhibit delayed-type hypersensitivity responses, block the access to T-lymphocytes by various regulatory factors by sitting on the surface of the cells (Hie-won et al., 1984; Worwood, 1990) and decrease leukocyte migration (Worwood, 1990). Receptors for $\mathrm{H}$-subunit rich ferritins have also been found on various T-cell lines, CD4 and CD8 T-lymphocytes and on CD19 B-lymphocytes, and the expression of H-subunit rich ferritin binding sites on these cells appears to be closely and positively linked to their activation and proliferation status (Meyron-Holtz et al., 1994; Morikawa et al., 1995). It would therefore appear that $\mathrm{H}$-subunit rich ferritins may perhaps act as feedback inhibitors of activation of peripheral blood cells in a way similar to that suggested for the cells involved in myelopoiesis. Quiescent circulating lymphocytes, reticulocytes, erythrocytes, and monocytes show little expression of the $\mathrm{H}$-subunit rich ferritin receptor, but PHA-stimulated lymphocytes, Epoinduced BFU cells and differentiated macrophages have all been shown to express above average levels of the receptor (Halliday et al., 1994), which may result in these cells being more susceptible to 
inhibition by $\mathrm{H}$-subunit rich ferritins. Increased binding of $\mathrm{H}$-subunit rich ferritins to peripheral lymphocytes have also been shown to occur in patients with malignant disorders and the magnitude of $\mathrm{H}$-subunit rich ferritin binding to lymphocytes was shown to be related to the stage of the malignant process (Ciriello et al., 1987). It is postulated that two receptor systems exist for the binding and execution of $\mathrm{H}$-subunit rich ferritin's effects. The first receptor system internalizes the bound ferritin. This system is similar to the receptor system operating in erythroid precursors. However, a regulatory effect on cell proliferation and maturation occurs whereas in erythroid precursors such a regulatory effect has not been observed (Meyron-Holtz et al., 1994, 1999). The second receptor system, with a Kd three orders of magnitude lower, does not result in the internalization of the bound ferritin (Meyron-Holtz et al., 1994, 1999). This suggests a mechanism for the regulation of cellular proliferation and maturation by ferritin not involving iron or the sequestration of iron.

\section{In conclusion}

There can be no doubt that the primary function of ferritin is to regulate the bioavailability of iron and that both the $\mathrm{H}$-subunit, which contains the ferrox-idase centre for oxidation of $\mathrm{Fe}^{2+}$ to $\mathrm{Fe}^{3+}$, and the $\mathrm{L}$ subunit, which plays a paramount role in the subsequent nucleation of $\mathrm{Fe}^{3+}$ and growth of the iron core, are required for optimal control of this bioavailability. However, even in the context of the regulation of iron bioavailability, and the effects thereof, many questions about the exact mechanisms and about the interplay between the $\mathrm{H}$ - and L-subunits remain. It would in general appear that an increase in expression of the $\mathrm{H}$-subunit, especially during times of cellular stress such as occurs during inflammation, brings about rapid sequestration of iron. The $\mathrm{H}$-subunit with its active ferroxidase centre reduces the labile iron pool, which would result in increased IRP activity, decreased cellular proliferation and increased resistance to $\mathrm{H}_{2} \mathrm{O}_{2}$-induced oxidative stress-effects that are apparently down-regulated by prolonged iron overload or inhibition of the ferroxidase centre (Cozzi et al., 2002, 2004). Information on the influence of the degree to which L-ferritin is expressed is still somewhat contradictory. While it is generally accepted that the L-subunit assists the $\mathrm{H}$-subunit in enhancing the incorporation of iron into ferritin by providing the major nucleation sites the increased expression of the L-subunit or in the Lsubunit/H-subunit ratio of ferritin is important in cells responsible for iron storage of vast amounts of iron. Although the results of a number of studies point to a role for L-ferritin in limiting the bioavail-ability of iron (Kakhlon et al., 2001a, b; Orino et al., 2001; White \& Munro, 1988), dramatic increases in the levels of L-ferritin as seen in hereditary hyperfer-ritenemia cataract syndrome, constitutive down-regulation of L-ferritin due to a mutation in the L-subunit start codon (Cozzi et al., 2004) or modification of the levels of L-ferritin by transfection with siRNA and cDNA (Cozzi et al., 2004) do not, in general, seem to have a significant influence on iron availability or compartmentalization (Cozzi et al., 2004).

While the primary function of ferritin is generally considered that of an iron storage protein that regulates the bioavailability of iron, other functions, some related to iron bioavailability and others not, are emerging such as its role in cellular proliferation where L-ferritin seems to increase (Blatt \& Wharton, 1992; Cozzi et al., 2004; Kakhlon et al., 2002; Kikyo et al., 1994) and H-ferritin to decrease proliferation (Cozzi et al., 2004), in erythropoiesis where the H-subunit/L-subunit ratio is important in supporting iron supply for haemoglobin synthesis or storage of excess iron (Hodgetts et al., 1986) and its regulatory role in the immune system where $\mathrm{H}$-subunit rich ferritins suppress certain immune responses and downregulate myelopoiesis (Broxmeyer, 1984; Torti \& Torti, 1994). Of interest is the fact that the suggested opposing effects of $\mathrm{H}$ - and L-ferritin would appear to be mediated through different mechanisms with the 
suppressive function of $\mathrm{H}$-ferritin brought about by its effect on bioavailable iron with that of L-ferritin being independent of bioavailable iron (Cozzi et al., 2004). In addition, H-ferritin expression would appear to have antiapoptotic effects-not related to its iron-binding function (Cozzi et al., 2003).

Although we are still far from understanding the exact role of ferritin and its isoforms in health and disease new information on the functions of ferritin and the movement of iron within the protein shell is surfacing. Information on the recently identified mitochondrial ferritin (Drysdale et al., 2002; Levi et al., 2001), a ferritin molecule with biochemical properties very similar to $\mathrm{H}$-ferritin provides, for instance, new insight into the movement of iron within the ferritin protein shell rich in $\mathrm{H}$-subunits (Langlois d'Estaintot et al., 2004).

\section{References}

Aisen P. 1991. Ferritin receptors and the role of ferritin in iron transport. Targeted Diag Ther 4:339 - 4 .

Agrawal R, Sharma PK, Rao, GS. 2001. Release of iron from ferritin by metabolites of benzene and superoxide radical generating agents. Toxicol 168:223 - 30 .

Alvarez-Hernández X, Licéga J, McKay IC, Brock JH. 1989. Induction of hypoferremia and modulation of macrophage iron metabolism by tumor necrosis factor. Lab Invest 61(3): $319-22$.

Arosio P, Yokota M, Drysdale JW. 1976. Structural and immunological relationships of isoferritins in normal and malignant cells. Cancer Res 36:1735 - 9.

Arosio P, Adelman TG, Drysdale JW. 1978. On ferritin heterogeneity; further evidence for heteropolymers. J Biol Chem 253(12):4451- 8 .

Arosio P, Levi S, Santambrogio P, Cozzi A, Luzzago A, Cesareni G, Albertini A. 1991. Structural and functional studies of human ferritin $H$ and $L$ chains. Curr Stud Hematol Blood Transf 58:127 - 31.

Bellotti V, Arosio P, Cazzola M, Cozzi A, Levi S, Meloni E, Zappone E. 1987. Characteristics of a ferritin-binding protein present in human serum. Br J Haematol 65(4):489 - 93.

Blatt J, Wharton V. 1992. Stimulation of growth of neuroblastoma cells by ferritin in vitro. J Lab Clin Med 119:139 - 43.

Bomford A, Conlon-Hollingshead C, Munro HN. 1981. Adaptive responses of rat tissue isoferritins to iron administration. J Biol Chem 256(2):948 - 55 .

Bou-Abdallah F, Arosio P, Santambrogio P, Yang X, Janus-Chandler C, Chasteen ND. 2002. Ferrous iron binding to recombinant human $\mathrm{H}$-chain. An isothermal titration calorimetry study. Biochem 41:11184-91.

Bou-Abdallah F, Biasiotto G, Arosio P, Chasteen ND. 2004. The putative 'nucleation site' in human H-chain ferritin is not required for mineralization of the iron core. Biochem 43:4332 - 7 .

Bou-Abdallah F, Santambrogio P, Levi S, Arosio P, Chasteen ND. 2005. Unique iron binding and oxidation properties of human mitochondrial ferritin: a comparative analysis with human $\mathrm{H}$-chain ferritin. J Mol Biol 347:543 - 54

Boyd D, Vecoli C, Belcher DM, Jain SK, Drysdale JW. 1985. Structural and functional relationships of human ferritin H and L chains deduced from cDNA clones. J Biol Chem 260(21): $11755-61$.

Brittenham GM. 1994. The red cell cycle. In: Brock JH, Halliday JW, Pippard MJ, Powell LW, editors. Iron metabolism in health and disease. London: WB Saunders Company Ltd. pp $31-62$.

Broxmeyer HE, Gentile P, Listowsky I, Cavanna E, Feickert HJ, Dorner MH, Ruggeri G, Cazzola M, Cooper S. 1984. Acidic isoferritins in the regulation of hematopoiesis in vitro and in vivo. In: Albertini A, Arosio P, Chiancone E, Drysdale J, editors. Ferritins and isoferritins as biochemical markers. Amsterdam: Elsevier Science Publishers. pp $97-111$.

Broxmeyer HE, Lu L, Bicknell DC, Williams DE, Cooper S, Levi S, Salfeld J, Arosio P. 1986. The influence of purified recombinant human heavy-subunit and light-subunit ferritins on colony formation in vitro by granulocyte-macrophage and erythroid progenitor cells. Blood 68(6): $1257-63$.

Broxmeyer HE, Cooper S, Levi, S, Arosio P. 1991. Mutated recombinant human heavy-chain ferritins and myelosuppression in vitro and in vivo: a link between ferritin ferroxidase activity and biological function. Proc Natl Acad Sci USA 88:770 - 4.

Broxmeyer HE. 1992. H-ferritin: A regulatory cytokine that down-modulates cell proliferation. J Lab Clin Med 120(3):367 - 70.

Broyles RH, Belegu V, DeWitt CR, Shah SN, Stewart CA, Pye QN, Floyd RA. 2001. Specific repression of $\beta$-globin promoter activity by nuclear ferritin. Proc Natl Acad of Sci USA 98(16):9145 - 50.

Cazzola M, Dezza L, Bergamaschi G, Barosi G, Bellotti V, Caldera D, Ciriello MM, Quaglini S, Arosio P, Ascari E. 1983. Biologic and clinical significance of red cell ferritin. Blood 62(5):1078-87.

Cazzola M, Ascari A. 1986. Red cell ferritin as a diagnostic tool. Br J Haematol 62(2):209 - 13.

Cazzola M, Invernizzi R, Bergamaschi G, Levi S, Corsi B, Travaglino E, Rolandi V, Biasiotto G, Drysdale J, Arosio P. 2003. Mitochondrial ferritin expression in erythroid cells from patients with sideroblastic anemia. Blood 101(5):1996 - 2000.

Chasteen ND. 1998. Ferritin. Uptake, storage, and release of iron. Met lons Biol Syst 35:479-514.

Chasteen ND, Harrison PM. 1999. Mineralization in ferritin: An efficient means of iron storage. J Struct Biol 126:182 - 94.

Cheepsunthorn P, Palmer C, Connor JR. 1998. Cellular distribution of ferritin subunits in postnatal rat brain. J Comp Neurol 400:73-86.

Chiancone E, Stefanini S. 1984. Heterogeneity of ferritin. I. Structural and functional aspects. In: Albertini A, Arosio P, Chiancone E, Drysdale J, editors. Ferritins and isoferritins as biochemical markers. Amsterdam: Elsevier Science Publishers. pp 23-32.

Ciriello MM, Cazzola, M, Dezza L, Levi S, Arosio P. 1987. Measurement of ferritin-bearing lymphocytes in man. Preliminary 
studies on the use of monoclonal antibodies specific for the $L$ and $H$ subunits of ferritin. Tumori $73: 37-41$.

Coccia EM, Profita V, Fiorucci G, Romeo G, Affrabi SE, Testa U, Hentze MW, Battistini A. 1992. Modulation of ferritin H-chain expression in Friend erythroleukemia cells: transcriptional and translational regulation by hemin. Mol Cell Biol 12(7):3015 22.

Connor JR, Boeshore KL, Benkovic SA, Menzies SL. 1994. Isoforms of ferritin have a specific cellular distribution in the brain. J Neurosci Res 37(4):461 - 5.

Corsi B, Cozzi A, Arosio P, Drysdale J, Santambrogio P, Campanella A, Biasiotto G, Albertini A, Levi S. 2002. Human mitochondrial ferritin expressed in HeLa cells incorporates iron and affects cellular iron metabolism. J Biol Chem 277(25): $22340-437$.

Covell AM, Worwood M. 1984. Isoferritins in plasma. In: Albertini A, Arosio P, Chiancone E, Drysdale J, editors. Ferritins and isoferritins as biochemical markers. Amsterdam: Elsevier Science Publishers. pp $49-65$.

Cozzi A, Corsi B, Levi S, Santambrogio P, Albertini A, Arosio, P. 2000. Overexpression of wild type and mutated human ferritin H-chain in HeLa cells. J Biochem 275(33): 25122 - 9.

Cozzi A, Corsi B, Levi S, Santambrogio P, Albertini A, Arosio, P. 2002. Overexpression of wild type and mutated human ferritin $\mathrm{H}$-chain in HeLa cells: in vivo role of ferroxidase activity. J Biol Chem 275:25122-9.

Cozzi A, Levi S, Corsi B, Santambrogio P, Campanella A, Gerardi G, Arosio P. 2003. The role of iron and ferritin in TNFainduced apoptosis in HeLa cells. FEBS Lett 537:187 - 92.

Cozzi A, Corsi, B, Levi S, Santambrogio P, Biasiotto G, Arosio P. 2004. nalysis of the biological functions of H- and L-ferritins $\mathrm{n}$ HeLa cells by transfection with siRNAs and cDNA: Evidence for a proliferative role of ferritin. Blood 103(6): $2377-83$.

Cragg SJ, Wagstaff M, Worwood M. 1981. Detection of a glycosylated subunit in human serum ferritin. Biochem J 199:565 - 71.

Deiss A. 1983. Iron metabolism in reticuloendothelial cells. Semin Hematol 20(2):81 - 90.

Drysdale J, Arosio P, Invernizzi R, Cazzola M, Volz A, Corsi B, Biasiotto G, Levi S. 2002. Mitochondrial ferritin: a new player in iron metabolism. Blood Cell Mol Dis 29(3): $376-83$.

Fahmy M, Young SP. 1993. Modulation of iron metabolism in monocyte cell line U937 by inflammatory cytokines: changes in transferrin uptake, iron handling and ferritin mRNA. Biochem J 296:175 - 81.

Fargion S, Arosio P, Fracanzani AL, Cislaghi V, Levi S, Cozzi A, Piperno A, Fiorelli G. 1988. Characteristics and expression of binding sites specific for ferritin $\mathrm{H}$-chain on human cell lines. Blood 71:753 - 7 .

Festa M, Ricciardelli G, Mele G, Pietropaolo C, Ruffo A, Colonna A. 2000. Overexpression of H ferritin and up-regulation of iron regulatory protein genes during differentiation of 3T3-L1 pre-adipocytes. J Biol Chem 275(47):36708 - 12.

Finch CA, Huebers HA, Cazzola M, Bergamaschi G, Bellotti V. 1984. Storage iron. In: Albertini A, Arosio P, Chiancone E, Drysdale J, editors. Ferritins and isoferritins as biochemical markers. Amsterdam: Elsevier Science Publishers. pp $3-21$.

Fischbach FA, Gregory DW, Harrison PM, Hoy TJ, Williams JM. 1971. On the structure of hemosiderin and its relationship to ferritin. J Ultrastr Res 37:495 - 503.

Ford GC, Harrison PM, Rice DW, Smith JM, Treffry A, White JL, Yariv J. 1984. Ferritin: design and formation of an iron-storage molecule. Phil Trans R Soc Lond 304:551 - 65.

Gálvez N, Ruiz B, Cuesta R, Colacio E, Dominguez-Vera JM. 2005. Release of iron from ferritin by aceto- and benzohydroxamic acids. Inorg Chem 44(8):2706 - 9.

Gelvan D, Fibach E, Meyron-Holtz EG, Konijn AM. 1996. Ferritin uptake by human erythroid precursors is a regulated iron uptake pathway. Blood 88(8):3200 - 7.

Halliday JW, Mack U, Powell LW. 1979. The kinetics of serum and tissue ferritins: relation to carbohydrate content. Br $\mathrm{J}$ of Haematol 42:535 - 46.

Halliday JW, Powell LW. 1979. Serum ferritin and isoferritins in clinical medicine. Progr Hematol 11:229 - 66.

Halliday JW, Ramm GA, Moss D, Powell LW. 1994. A new look at ferritin metabolism. Adv Exp Med Biol 365:149 - 56.

Harford JB, Rouault TA, Klausner RD. 1994. The control of cellular iron homeostasis. In: Brock JH, Halliday JW, Pippard MJ, Powell LW, editors. Iron metabolism in health and disease. W.B. Saunders Company Ltd. London. pp $123-49$.

Harrison PM, Arosio P. 1996. The ferritins: molecular properties, iron storage function and cellular regulation. Biochim Biophys Acta 1275:161 - 203.

Hasan MR, Morishima D, Tomita K, Katsuki M, Kotani S. 2005. Identification of a $250 \mathrm{kDa}$ putative microtubule-associated protein as a bovine ferritin; evidence for a ferritin-microtubule interaction. FEBS J 272:822 - 31.

Hershko C, Konijn AM. 1984. Serum ferritin in hematologic disorders. In: Albertini A, Arosio P, Chiancone E, Drysdale J, editors. Ferritins and isoferritins as biochemical markers. Amsterdam: Elsevier Science Publishers. pp $143-58$.

Hie-won L, Stahlhut MW, \& Evans AE. 1984. Isoferritins and prognosis of neuroblastoma: the immunological role of acidic isoferritins. In: Albertini A, Arosio P, Chiancone E, Drysdale J, editors. Ferritins and isoferritins as biochemical markers. Amsterdam: Elsevier Science Publishers. pp $171-80$.

Hodgetts J, Peters SW, Hoy TG, Jacobs A. 1986. The ferritin content of normoblasts and megaloblasts from human bone marrow. Clin Sci 70:47-51.

Hulet SW, Heyliger SO, Powers S, Connor JR. 2000. Oligodendrocyte progenitor cells internalize ferritin via clathrin-ependent receptor mediated endocytosis. J Neurosci Res 61:52 - 60.

Hwang J, Krebs C, Huynh BH, Edmondson DE, Theil EC, Penner-Hahn JE. 2000. A short Fe-Fe distance in peroxodiferric ferritin: control of Fe substrate versus cofactor decay? Science 287(5450):122 - 5 .

Hynes MJ, Coinceanainn MO. 2002. Investigation of the release of iron from ferritin by naturally occurring antioxidants. J Inorg Biochem 90:18 - 21

lancu TC. 1982. Iron overload. Mol Aspects Med 6:1 - 100.

lancu TC. 1992. Ferritin and hemosiderin in pathological tissues. Electron Microsc Rev 5:209 - 29.

Invernizzi R, Caccola M, De Fazio P, Rosti V, Ruggeri G, Arosio P. 1990. Immunocytochemical detection of ferritin in human bone marrow and peripheral blood cells using monoclonal antibodies specific for the $\mathrm{H}$ and $\mathrm{L}$ subunit. Br $\mathrm{J} H a e m a t o l ~ 76: 427$ -32 .

Jacobs A, Worwood M. 1975. Ferritin in serum; clinical and biochemical implications. New Engl J Med 292(18):951 - 6.

Jacobs A. 1977. Low molecular weight intracellular iron transport compounds. Blood 50(3):433-9. 
Jacobs A, Hodgetts J, Hoy TG. 1984. Functional aspects of isoferritins. In: Albertini A, Arosio P, Chiancone E, Drysdale J, editors. Ferritins and isoferritins as biochemical markers. Amsterdam: Elsevier Science Publishers. pp $113-27$.

Jameson GNL, Jameson RF, Linert W. 2004. New insights into iron release from ferritin: direct observation of the neurotoxin 6hydroxydopamine entering ferritin and reaching redox equilibrium with the iron core. Org Biomol Chem 2:2346 - 51.

Jin W, Hidnori T, Pancorbo B, Theil EC. 2001. 'Opening' the ferritin pore for iron release by mutation of conserved amino acids at interhelix and loop sites. Biochem 40:7525 - 32 .

Jones BM, Worwood M, Jacobs A. 1983. Isoferritins in normal leucocytes. Br J Haematol 55(1):73-81.

Joshi JG, Clauberg M. 1988. Ferritin: an iron storage protein with diverse functions. Biofactors 1(3):207 - 12.

Kakhlon O, Gruenbaum, Y, Cabantchik ZI. 2001a. Repression of the heavy chain increases the labile iron pool of human K562 cells. Biochem J 356(2):311 - 16.

Kakhlon O, Gruenbaum Y, Cabantchik Zl. 2001b. Repression of ferritin expression increases the labile iron pool, oxidative stress, and short-term growth of human erythroleukemia cells. Blood 97:2863 - 71.

Kakhlon O, Gruenbaum Y, Cabantchik ZI. 2002. Ferritin expression modulates cell cycle dynamics and cell responsiveness to $\mathrm{H}$-ras-induced growth via expansion of the labile iron pool. Biochem J 363(3):431 - 6 .

Kew MC, Torrance JD, Derman D, Simon M, Macnab GM, Charlton RW, Bothwell TH. 1978. Serum and tumour ferritins in primary liver cancer. Gut 19(4):294 - 9.

Kikyo N, Suda M, Kikyo N, Hagiwara K, Yasukawa K, Fujisawa M, Yazaki Y, Okabe T. 1994. Purification and characterization of a cell growth factor from a human leukaemia cell line: immunological identity with ferritin. Cancer Res 54:268 - 71.

Kim S-W, Kim Y-H, Lee J. 2001. Thermal stability of human ferritin: concentration dependence and enhanced stability of an Nterminal fusion mutant. Biochem Biophys Res Commun 289:125 - 9.

Konijn AM, Meyron-Holtz EG, Fibach E, Gelvan, D. 1994. Cellular ferritin uptake: a highly regulated pathway for iron assimilation in human erythroid precursor cells. Adv Exp Med Biol 356:189 - 97.

Langlois d'Estaintot B, Santambrogio P, Granier T, Gallois B, Chevalier JM, Precigoux G, Levi S, Arosio P. 2004. Crystal structure and biochemical properties of the human mitochondrial ferritin and its mutant Ser144Ala. J Mol Biol 340(2): 277 93.

Lawson DM, Treffry A, Artymiuk PL, Harrison PM, Yewdall SJ, Luzzago A, Cesareni G, Levi S, Arosio P. 1989. Identification of the ferroxidase centre in ferritin. FEBS Lett 254(1/2): $207-10$.

Levay PF, Viljoen M. 1995. Lactoferrin: a general review. Haematologica 80(3):252 - 67.

Levi S, Luzzago A, Franceschinelli F, Santambrogio P, Cesareni G, Arosio P. 1989. Mutational analysis of the channel and loop sequences of human ferritin H-chain. Biochem J 264:381 - 8.

Levi S, Yewdall SJ, Harrison PM, Santambrogio P, Cozzi A, Rovida E, Albertini A, Arosio P. 1992. Evidence that H- and Lchains have co-operative roles in the iron-uptake mechanisms of human ferritin. Biochem J 288:591 - 6 .

Levi S, Santambrogio P, Cozzi A, Rovida E, Corsi B, Tamborini E, Spada S, Albertini A, Arosio P. 1994. The role of the L-chain in ferritin iron incorporation; studies of homo and heteropolymers. J Mol Biol 238:649 - 54.

Levi S, Santambrogio P, Corsi B, Cozzi A, Arosio P. 1996. Evidence that residues exposed on the three-fold channels have active roles in the mechanism of ferritin iron incorporation. Biochem J 317(2):467 - 73.

Levi S, Corsi B, Bosisio M, Invernizzi R, Volz A, Sanford D, Arosio P, Drysdale J. 2001. A human mitochondrial ferritin encoded by an intronless gene. J Biol Chem 270(27): $24437-40$.

Levi S, Arosio P. 2004. Mitochondrial ferritin. Int J Biochem Cell Biol 36:1887 - 9.

Liu X, Jin W, Theil EC. 2003. Opening protein pores with chaotropes enhances Fe reduction and chelation of Fe from the ferritin biomineral. PNAS 100(7):3653 - 8.

Liu X, Theil EC. 2004. Ferritin reactions: direct identification of the site for the diferric peroxide reaction intermediate. PNAS 101(23):8557-62.

Martsev SP, Vlasov AP, Arosio P. 1998. Distinct stability of recombinant $L$ and $H$ subunits of human ferritin: calori-metric and ANS binding studies. Protein Eng 11(5):377 - 81.

Mehlhase J, Sandig G, Pantopoulos K, Grune T. 2005. Oxidation-induced ferritin turnover in microglial cells: role of proteasome. Free Rad Biol Med 38:276 - 85.

Meyron-Holtz EG, Fibach E, Gelvan D, Konijn AM. 1994. Binding and uptake of exogenous isoferritins by cultured human erythroid precursor cells. $\mathrm{Br} \mathrm{J}$ Haematol 86: $635-41$.

Meyron-Holtz EG, Vaisman B, Cabantchik ZI, Fibach E, Rovault TA, Hershko C, Konijn AM. 1999. Regulation of intracellular iron metabolism in human erythroid precursors by internalized extracellular ferritin. Blood 94(9):3205 - 11.

Miyazaki E, Kato J, Kobune M, Okumura K, Sasaki K, Shintani N, Arosio P, Niitsu Y. 2002.Denatured H-ferritin subunit is a major constituent of haemosiderin in the liver of patients with iron overload. Gut 50:413 - 19.

Morikawa K, Oseko F, Morikawa S. 1995. A role for ferritin in hematopoiesis and the immune system. Leuk Lymphoma 18:429 33.

Moss D, Hibbs AR, Stenzel D, Powell LW, Halliday JW. 1994. The endocytic pathway for H-ferritin established in live MOLT-4 cells by laser scanning confocal microscopy. Br J Haematol 88:746 - 53 .

Nie G, Sheftel AD, Kim SF, Ponka P. 2005. Overexpression of mitochondrial ferritin causes cytosolic iron depletion and changes cellular iron homeostasis. Blood 105(5):2161 - 7.

Niitsu Y, Onodera Y, Kohgo Y, Goto Y, Watanabe N, Urushizaki I. 1984. Isoferritins in malignant diseases. In: Albertini A, Arosio $\mathrm{P}$, Chiancone E, Drysdale J, editors. Ferritins and isoferritins as biochemical markers. Amsterdam: Elsevier Science Publishers. pp $113-27$.

Orino K, Lehman L, Tsuji Y, Ayaki H, Torti SV, Torti FM. 2001. Ferrritin and the response to oxidative stress. Biochem J 357:241 $-7$.

Persson HL, Nilsson KJ, Brunk UT. 2001. Novel cellular defences against iron and oxidation: ferritin and autophagocytosis preserve lysosomal stability in airway epithelium. Redox Report 6(1):57 - 63.

Piñero DJ, Hu J, Cook BM, Scaduto Jr, RC, Connor JR. 2000. Interleukin-1 $\beta$ increases binding of the iron regulatory protein and the synthesis of ferritin by increasing the labile iron pool. Biochim Biophys Acta 1497:279 - 88 .

Polanams J, Ray AD, Watt RK. 2005. Nanophase iron phosphate, iron arsenate, iron vanadate and iron molybdate minerals 
synthesized within the protein cage of ferritin. Inorg Chem 44(9):3203 - 9.

Ponka P, Beaumont C, Richardson DR. 1998. Function and regulation of transferrin and ferritin. Sem Hematol 35(1):35 - 54.

Powell LW, Alpert E, Isselbacher KJ, Drysdale JW. 1975. Human isoferritins: organ specific iron and apoferritin distribution. Br J Haematol 30:47 - 132

Powell AK. 1998. Ferritin. Its mineralization. Met lons Biol Syst 35:515 - 61.

Radisky DC, Kaplan J. 1998. Iron in cytosolic ferritin can be recycled through lysosomal degradation in human fibroblasts. Biochem J 336:201 - 5.

Richter GW. 1978. The iron-loaded cell-the cytopathology of iron storage. Am J Pathol 91(2):363 - 404.

Richter GW. 1984. Studies of iron overload; rat liver siderosome ferritin. Lab Invest 50(1):26 - 35.

Ringeling PL, Cleton MI, Kroos MJ, Sorber LWJ, de Bruyn WC, Harrison PM, van Eijk HG. 1989. Lysosomal and cytosolic ferritins. Biol Metals 2:114 - 21 .

Rogers J, Lacroix L, Durmowitz G, Kasschau K, Andriotakis J, Bridges KR. 1994. The role of cytokines in the regulation of ferritin expression. Adv Exp Med Biol 356:127 - 32.

Rudeck M, Volk T, Sitte N, Grune, T. 2000. Ferritin oxidation in vitro: implication of iron release and degradation by the $20 \mathrm{~S}$ proteasome. IUBMB Life 49:451 - 6 .

Ruggeri G, lacobello C, Albertini A, Brocchi E, Levi S, Gabri E, Arosio P. 1984. Studies of human isoferritins in tissues and body fluids. In: Albertini A, Arosio P, Chiancone E, Drysdale J, editors. Ferritins and isoferritins as biochemical markers. Elsevier Science Publishers. Amsterdam. pp $67-78$.

Ruggeri G, Santambrogio P, Bonfiglio F, Levi S, Bugari G, Verardi R, Cazzola M, Invernizzi R, Zambelli LM, Albertini A, Arosio $\mathrm{P}$. 1992. Antibodies for denatured human $\mathrm{H}$-ferritin stain only reticuloendothelial cells within the bone marrow. Br J Haematol $81: 118-24$.

Sánchez P, Gálvez N, Colacio E, Miñones E, Domínguez-Vera JM. 2005. Catechol releases iron(III) from ferritin by direct chelation without iron(II) production. Dalton Trans 4:811 - 13.

Santambrogio P, Levi S, Cozzi A, Rovida E, Albertini A, Arosio P. 1993. Production and characterization of recombinant heteropolymers of human ferritin $\mathrm{H}$ and L chains. J Biol Chem 268(7):12744 - 48.

Santambrogio P, Levi S, Cozzi A, Corsi B, Arosio P. 1996. Evidence that the specificity of iron incorporation into homopolymers of human ferritin L- and $\mathrm{H}$-chains is conferred by the nucleation and ferroxidase centres. Biochem J 314: $139-44$.

Siegenberg D, Baynes RD, Bothwell TH, Macfarlane BJ, Lamparelli RD. 1990. Factors involved in the regulation of iron transport through reticuloendothelial cells. Proc Soc Exp Biol Med 193(1):65 - 72.

Speyer BE, Fielding J. 1979. Ferritin as a cytosol iron transport intermediate in human reticulocytes. Br J Haematol 42:255 - 67.

Surguladze N, Thompson KM, Beard JL, Connor JR, Fried MG. 2004. Interactions and reactions of ferritin with DNA. J Biol Chem 279(15):14694 - 702.

Surguladze N, Patton S, Cozzi A, Fried MG, Connor JR. 2005. Characterization of nuclear ferritin and mechanism of translocation. Biochem J 388:731 - 40.

Takagi H, Shi D, Ha Y, Allewell NM, Theil EC. 1998. Localized unfolding at the junction of three ferritin subunits; a mechanism for iron release. J Biol Chem 273(30):18685 - 8.

Takahashi T, Kuyucak S. 2003. Functional properties of three-fold and fourfold channels in ferritin deduced from electrostatic calculations. Biophys J 84:2256 - 63 .

Theil EC. 1990. The ferritin family of iron storage proteins. Adv Enzymol Relat Areas Mol Biol 63:421 - 49.

Theil EC. 1990. Ferritin and mRNA translation, structure, and gene transcription during development of animals and plants. Enzyme 44(1-4):68 - 82.

Thompson KJ, Fried MG, Ye Z, Boyer P, Connor JR. 2002. Regulation, mechanisms and proposed function of ferritin translocation to cell nuclei. J Cell Sci 115:2165 - 77.

Thomson AM, Rogers JT, Leedman PJ. 1999. Iron-regulatory proteins, iron-responsive elements and ferritin mRNA translation. Int J Biochem Cell Biol 31:1139 - 52.

Torti FM, Torti SV. 2002. Regulation of ferritin genes and protein. Blood 99(10):3505 - 16.

Torti SV, Torti FM. 1994. Iron and ferritin in inflammation and cancer. Adv Inorg Biochem 10:119-37.

Treffry A, Zhao Z, Quail MA, Guest JR, Harrison PM. 1997. Dinuclear centre of ferritin: studies of iron binding and oxidation show differences in the two iron sites. Biochem 36:432 - 41.

Truty J, Malpe R, Linder MC. 2001. Iron prevents ferritin turnover in hepatic cells. J Biol Chem 276(52):48775 - 80 .

Wade VJ, Levi S, Arosio P, Treffry A, Harrison PM, Mann S. 1991. Influence of site-directed modifications on the formation of iron cores in ferritin. J Mol Biol 221:1443- 52.

Wagstaff M, Worwood M, Jacobs A. 1982. Iron and isoferritins in iron overload. Clin Sci 62(5):529 - 40.

Watt GD, Frankel RB, Papaefthymiou GC. 1985. Reduction of mammalian ferritin. Proc Natl Acad Sci USA 82:3640 - 3.

Weir MP, Sharp GA, Peters TJ. 1985. Electron microscopic studies of human haemosiderin and ferritin. J Clin Pathol 38:915 8.

Welch KD, Van Eeden MC, Aust SD. 2001. Modification of ferritin during iron loading. Free Rad Biol Med 31(8):999 - 1006.

Welch KD, Reilly CA, Aust SD. 2002. The role of cysteine residues in the oxidation of ferritin. Free Rad Biol Med 33(3):399 408.

White K, Munro HN. 1988. Induction of ferritin subunit synthesis by iron is regulated at both the transcriptional and translational levels. J Biol Chem 263(18):8938 - 42.

Wixom RL, Prutkin L, Munro HN. 1980. Hemosiderin: nature, formation, and significance. Int Rev Exp Pathol 22:193 - 225.

Worwood M, Dawkins S, Wagstaff M, Jacobs A. 1976. The purification and properties of ferritin from human serum. Biochem J 157:97-103.

Worwood M. 1982. Ferritin in human tissues and serum. Clin Haematol 11(2):275 - 307.

Worwood M. 1990. Ferritin. Blood Rev 4:259 - 69. 